Max-Planck-Institut für demografische Forschung

Max Planck Institute for Demographic Research

Konrad-Zuse-Strasse 1 - D-18057 Rostock - GERMANY

Tel +49 (0) 3812081 - 0; Fax +49 (0) 3812081 - 202;

http://www.demogr.mpg.de

MPIDR WORKING PAPER WP 2011-017

OCTOBER 2011 (REVISED NOVEMBER 2013)

\title{
High development and fertility: \\ Fertility at older reproductive ages and gender equality explain the positive link
}

\author{
Mikko Myrskylä (M.Myrskyla@lse.ac.uk) \\ Hans-Peter Kohler \\ Francesco C. Billari
}

(C) Copyright is held by the authors.

Working papers of the Max Planck Institute for Demographic Research receive only limited review. Views or opinions expressed in working papers are attributable to the authors and do not necessarily reflect those of the Institute. 


\title{
Corresponding Author:
}

\author{
Mikko Myrskylä \\ Department of Social Policy \\ London School of Economics and Political Science \\ Houghton Street, London WC2A 2AE, United Kingdom \\ Email: M.Myrskyla@lse.ac.uk \\ Phone +44 (0)20 79556646
}

\begin{abstract}
FULL TITLE: High development and fertility: Fertility at older reproductive ages and gender equality explain the positive link
\end{abstract}

\begin{abstract}
SHORT TITLE: Development, fertility and gender equality
\end{abstract}
Word count, abstract: 145

Word count, main text: 7,454

\author{
Mikko Myrskylä [1] \\ Hans-Peter Kohler [2] \\ Francesco C. Billari [3]
}

[1] London School of Economics and Political Science

[2] Population Studies Center and Department of Sociology, University of Pennsylvania [3] Department of Sociology and Nuffield College, University of Oxford 


\begin{abstract}
A fundamental reversal of the traditional fertility-development relationship has occurred in highly developed countries so that further socioeconomic development is no longer associated with decreasing fertility, but with increasing fertility. In this paper, we seek to shed light on the mechanisms underlying this reversal by analyzing data from 1975 to 2008 for over 100 countries. We find that the reversal exists from both the period and the cohort perspectives, and is mainly driven by increasing fertility at older reproductive ages. Further, the reversal is only partially explained by changes in the timing of fertility. However, the positive impact of development on fertility is conditional on gender equality: countries that rank high in development as measured by health, income, and education, but low in gender equality, continue to experience declining fertility. This finding demonstrates the importance of work-family balance in shaping fertility at older reproductive ages.
\end{abstract}

Key words: Low fertility, Socioeconomic Development, Gender Equality, Tempo-Adjusted Fertility, Postponement, Panel Data 


\section{Introduction}

Persistent below-replacement fertility is one of the key demographic and policy challenges in highly developed societies. Low and very low fertility have also spread to some middle-income countries, and sustained periods of low fertility are projected for many countries that currently have fertility above or near the replacement level (United Nations Population Division 2011). For example, according to the UN's medium-term projections fertility in South America and Asia will drop below the replacement level by 2020-2025. In one speculative extrapolation of current trends, Wilson (2011:382) even states that “[o]ver a somewhat longer time frame, we cannot exclude the possibility of a reversed differential, with higher fertility in the rich world than in the poor.” Already since late 2003, the majority of the world's population have been living in areas with below-replacement fertility levels (Morgan and Taylor 2006; Wilson 2004).

Worried about these fertility trends, the European Commission (2005) has identified the decline in fertility to below 1.5 children per woman as being among the key challenges for policy-makers. Most countries with a period total fertility rate below 1.5 are currently attempting to increase their rate through the implementation of specific policies (United Nations 2010). The OECD explicitly promotes the idea that people should be provided with the means to realize their plans to have children, based on the notion that people are having fewer children than they

actually want, and that policies and environments that favor a better work-family balance and gender equality could enhance fertility (OECD 2011).

Concerns about low fertility are based on past and anticipated trends in period total fertility rates (TFR). In accordance with standard demographic transition theory (e.g., Kirk, 1996), until very recently, the negative association between fertility and development was one of the most acknowledged stylized facts and theoretical constructs in the population development debate (Bongaarts and Watkins 1996; Bryant 2007; Lee 2003). Although socioeconomic 
development was not the leading explanation for fertility differential and trends, the idea that fertility decline was unlikely to be reversed (Bongaarts 1998; Butler 2004; Frejka and Calot 2001; Kohler, Billari and Ortega 2002; Lutz, O'Neill and Scherbov 2003; Lutz, Sanderson and Scherbov 2008) was consistent with the concept of a negative development-fertility link.

Recently, however, the notion that fertility will continue to decline among advanced countries has been challenged. Myrskylä, Kohler, and Billari (2009) found that while development continues to promote fertility declines among countries at low and medium levels of development, further increases in development lead to increases in fertility among counties with advanced levels of development. This finding is consistent with the literature documenting fertility increases for many developed countries before the recession starting in the late 2000s (Goldstein, Sobotka and Jasilioniene 2009; Luci and Thevenon 2010; Sobotka 2008; Trovato 2010). Analyses of the most recent recession are also consistent with the positive developmentfertility link, and have shown a negative effect on fertility (Goldstein et al. 2013)

This article sheds light on the mechanisms underlying the reversal of the developmentfertility association by analyzing the links between development and age/cohort patterns of fertility, and by investigating the role of gender equality as a prerequisite for the reversal of this link. First, using data from 1975 to 2008 for over 100 countries, we show that the reversal is visible from both a period and a cohort perspective, and is mainly driven by increasing fertility among people of older reproductive ages. Analyses accounting for changes in the timing of childbearing suggest that while tempo effects contribute to the reversal, increases in the quantum of fertility are a significant component in the reversal. Second, we show that gender equality is a prerequisite for the reversal of the link between development and fertility. This is consistent with the importance of work-family balance in shaping fertility at older reproductive ages. Countries ranking high in development as measured by health, income, and education, but low in gender 
equality, continue to experience declining fertility. Various robustness tests presented below indicate that our findings are robust and do not change when different model specifications or alternative measures are used.

\section{Recent fertility increases in the developed countries: patterns and mechanisms}

In 2008, a total of 30 mostly advanced countries had period total fertility rates (TFR) below 1.5, and the average period fertility in 27 European Union countries was 1.6 (World Bank 2010). In developed East Asian countries fertility was even lower, averaging 1.2 for Singapore, Japan, South Korea, and Hong Kong (World Bank 2010). While these are historically low levels, for many countries they still represent an increase from the lowest levels observed in the 1980s and 1990s, as the TFR has recently been increasing in the majority of European countries. In the period 1998-2008, 18 European countries experienced TFR increases of 0.2 or more from the lowest levels (Bongaarts and Sobotka 2011; Goldstein et al. 2009). In the period 1998-2008, the TFR also increased in the U.S., Canada, the U.K. and Australia but continued to decline in the developed East Asian countries (World Bank 2010). However, the most recent recession seems to have influenced the trends in many developed countries so that fertility has declined or the prior positive trend has flattened (Goldstein et al. 2013)

For most developed countries, an increasing TFR can be seen as a positive change in the sense that increasing fertility may attenuate the pace of population aging and decline. The findings of Myrskylä et al. (2009) suggest that these fertility increases have been at least partially driven by continued socioeconomic progress. Consistent with past research on the fertilitydevelopment link (e.g., Bongaarts and Watkins 1996) Myrskylä et al. used the Human Development Index (HDI) to measure socioeconomic progress. Figure 1, which updates the analysis of Myrskylä et al. (2009) with the newly published data on the HDI from the UNDP 
(2011) and TFR data from the World Bank (2010), shows the cross-sectional relationship between fertility and development in 1975 and 2008. Based these recent data, Figure 1 demonstrates that fertility is negatively associated with development up to HDI levels of around 0.80-0.85, but that at higher levels of development, the association changes to positive. ${ }^{1}$

\section{FIGURE 1 HERE}

Despite these general findings, crucial questions regarding the reversal of the development-fertility link have yet to be answered. First, what are the age and cohort patterns associated with the reversal? Second, could the reversal in the fertility-development association be purely the effect of demographic measurement, and, in particular, of changes in the timing of fertility, which depressed the TFR in earlier years, but which have become less influential in recent years (Bongaarts 2002; Bongaarts and Feeney 1998; Goldstein et al. 2009; Sobotka 2004)? Third, as there are important exceptions to the positive relationship, what factors have contributed to the reversal? In particular, is a high level of gender equity, as an indicator of societal environments favoring the combining of work and family, a prerequisite for this reversal? We discuss the background of these aspects before proceeding with the empirical analyses.

Age and cohort patterns of the reversal in the fertility-development link

Throughout the developed world, fertility trends during recent decades - including during both fertility declines and recent increases in fertility - have been accompanied by an increasing mean age at first birth. On the one hand, the onset or a rapid pace of fertility postponement induces a downward distortion in commonly used period-indicators of fertility - such as the TFR - as compared to the quantum of fertility, which arguable more accurately reflects the underlying preferences and longer-term fertility behaviors (Bongaarts and Feeney 1998; Kohler and Ortega

\footnotetext{
${ }^{1}$ Appendix Figures A1a and A1b show the patterns without scaling of the axes and with confidence intervals.
} 
2004). On the other hand, when the pace of postponement slows down, the distortion may decrease, resulting in a tempo-driven TFR increase (Goldstein et al. 2009). Some of the observed recent increases in fertility, and the recent reversals in the development-fertility relationship might therefore be attributable to such tempo effects.

Our analyses of the age and cohort patterns and adjustments for the timing of fertility will prove useful in helping to understand the quantum versus the tempo nature of the fertility reversal. First, as fertility postponement means shifting births from younger to older ages, we expect to find that the reversal in period fertility is driven by fertility at older ages. Second, if the reversal is purely due to the effect of changes in the timing of fertility, we would expect to see no reversal when fertility measures that adjust for timing changes are used. In particular, a finding of no or a negative association between cohort fertility and development would support the concept of a "pure timing" mechanism. If, however, development increases fertility through changes in the quantum as well, we would expect to find a positive association between development and period fertility net of timing adjustments, and a similar positive association between development and cohort fertility.

\section{Gender equality and the reversal in the fertility-development link}

Independently on whether recent fertility increases, and the related positive associations between HDI and fertility, are driven by changes in the tempo of fertility or increases in the quantum of fertility, gaining a deeper understanding of the mechanisms driving the reversal in the link between fertility and development requires us to apply a theoretical perspective to the societallevel determinants of this link. Given the heterogeneity of the institutional, cultural, and policy contexts across the developed countries, the mechanism through which development becomes positively associated with fertility may not be unique, but it may be context-specific. 
According to McDonald (2000), the emergence of very low fertility is attributable to the lack of gender equity in a society, and in particular, to gender inequality and the asymmetric roles of women and men within households as compared to an increasing level of gender equality in the labor market and other domains of life outside the household. Esping-Andersen (2009) has argued that very low fertility is the by-product of the incomplete transition from an "old” genderunequal system based on the male breadwinner to a "new" gender-equal system in which housework, childrearing responsibilities and labor market participation (or earnings) are more gender-equally distributed within households. Based on these theoretical predictions, it is therefore natural to investigate gender equality as a potential precondition for the reversal of the development-fertility link. Countries rarely reach advanced levels of socioeconomic development without the large-scale participation of women in the labor force. The expansion of female labor force participation typically happens in a context in which the institutional infrastructure and the cultural traditions are not ready to accommodate women who both work and have children, and therefore leads, at least temporarily, to declining fertility. Gender equality becomes a key factor for the subsequent adjustment, and the simultaneous mobilization of the female labor supply and the promotion of gender equality in paid and unpaid work becomes a best practice policy target (OECD 2011).

While the findings on the effectiveness of individual policies are mixed, the overall literature suggests that gender-equality policies have an impact on fertility, although it is not clear whether these influences are changes in timing or in quantum (Gauthier 2007; Luci and Thevenon 2011; McDonald 2006; Neyer and Andersson 2008). When we consider gender equality as a potential precondition for the reversal of the development-fertility link, it becomes clear that the factors through which gender equality could channel the impact of development may be context-specific (Gauthier 2007; Thévenon 2011). For example, depending on the 
context, the mix of family-friendly policies may focus on providing support to working parents with young children, as is common in the Nordic countries, or on providing financial support targeted at low-income and large families, as is common in Anglo-Saxon countries (Frejka, Jones and Sardon 2010; Thévenon 2011). Moreover, policies that work in a certain context may be ineffective elsewhere. A prime example is childcare availability, which may have boosted fertility in Norway (Rindfuss et al. 2010). In Germany, where cultural norms are less favorable to working mothers (Ruckdeschel 2009), the expansion of childcare provision has arguably not yet had a measurable impact. Thus social norms are potentially important determinants of the mechanisms through which gender equality could influence the development-fertility association, and the efficacy of any policy is likely to be context-specific.

Nevertheless, the gap between the levels of desired fertility that are reported in surveys and the observed period TFRs (D'Addio and D’Ercole 2005; Goldstein et al. 2003; van Peer 2002) suggests that there is demand for policy environments that facilitate childbearing. The difficulties in combining family and work are often seen as an important factor limiting women and couples from realizing their fertility intentions. At advanced levels of development, governments may explicitly address low fertility by implementing policies that improve the compatibility between pursuing a career and raising children. Countries that have high levels of gender equality may be better able than countries that lag behind to develop the institutional structures and new cultural traditions that attenuate the family-work conflict. This will affect fertility at older reproductive ages in particular.

\section{Data and methods}

Fertility 
For period fertility, we use the total fertility rate (source: World Bank 2010) and the age-specific fertility rates at ages 15-29 and 30-49 (sources: United Nations 2011; Human Fertility Database HFD 2011; Eurostat 2011). The literature has uncovered weaknesses in the TFR (Sobotka and Lutz 2009), with the main critique being that the measure is subject to tempo effects. We therefore complement our period fertility analyses with the Bongaarts-Feeney (1998) tempoadjusted TFR (source: HFD 2011). We use information on the mean age at first birth and the overall mean age at birth (sources: please refer to the Appendix). For cohort fertility, we use completed fertility for the 1970 birth cohort using the data published in Myrskylä et al. (2013).

\section{Socioeconomic development}

We measure the level of socioeconomic development using the HDI, which is computed by the United Nations Development Programme (UNDP). The UNDP occasionally updates the exact definition of the HDI, and the only version of the HDI that is consistently comparable over time was introduced alongside the 2011 revision. We use this time-consistent index, which is calculated as the geometric mean of (i) the health conditions, which are measured by annual life expectancy at birth; (ii) the standard of living, which is measured by the logarithm of the annual gross domestic product (GDP) per capita at purchasing power parity (PPP) in US dollars; and (iii) the human capital, which is measured by the average of the adult literacy rate and the combined primary, secondary, and tertiary gross school enrolment ratio.

Myrskylä et al. (2009) used a previous UNDP definition of the HDI, which was based on an arithmetic average of the HDI components. As the correlations between the two HDI measures are high — 0.98 or higher for the years $1980-2008$ — it is unlikely that our results would be sensitive to the particular HDI measure used. The main difference between the old and the new HDI is that the new time-consistent index is on average 0.05 lower at high levels of development 
than the old index. Myrskylä et al. (2009) observed that the fertility-development association reversed in the HDI range of $0.85-0.90$; with the new time-consistent HDI, we expect to find that the reversal takes place at an HDI level that is 0.05 units lower. The appendix provides further details about the HDI measure.

\section{Gender equality}

We measure gender equality using the World Economic Forum's Global Gender Gap (GGG) index (Hausmann, Tyson and Zahidi 2010). The GGG measures gender equality, with high values indicating high levels of equality, and low values indicating low levels of equality (= gender inequality). The GGG aims to captures gaps in outcomes rather than gaps in means, aims, or instrumental and input variables, and is constructed based on the following components: 1 . economic participation (male and female unemployment levels, levels of economic activity, and remuneration for equal work); 2. economic opportunity (duration of maternity leave, number of women in managerial positions, availability of government-provided childcare, wage inequalities between men and women); 3. political empowerment (number of female ministers, share of seats in parliament, women holding senior legislative and managerial positions, number of years a female has been head of state); 4. educational attainment (literacy rates; enrolment rates for primary, secondary, and tertiary education; average years of schooling); and 5 . health and wellbeing (effectiveness of government efforts to reduce poverty and inequality, adolescent fertility rate, percentage of births attended by skilled health staff, maternal and infant mortality rates).

The GGG is based on an innovative set of measurement techniques, which combine quantitative data with qualitative measures from the Executive Opinion Survey of the World Economic 
Forum, a survey of 9,000 business leaders in 104 countries. Basing the index on such measures, even if only partially, comes at a cost. While it is a nuanced and comprehensive measure, one of the shortcomings of the GGG is that its data requirements are complex. Consequently, the index is available mostly for countries with medium to high levels of development. Alternative indexes, such as the UNDP's Gender-related Development Index (GDI) or the Gender Empowerment Measure (GEM) also cover less developed countries. This limitation of the GGG is, however, not important for the current paper, because our focus is on highly developed countries.

An important feature of the GGG index is that it measures gaps rather than levels. Thus, the index may have high values in a deprived context (or in countries with a low HDI) as long as men and women are equally deprived. This sets the index apart from some other commonly used gender equality indexes, such as the GEM or the GDI. The GDI measures achievement in the same basic areas as the HDI, but imposes a penalty for inequality: i.e., the GDI falls when the achievement levels of both women and men go down or when the disparity between them increases. Consequently, the GDI tends to be highly correlated with the HDI, and adds comparatively little value to our analysis, which already includes the HDI. Another index, the UNDPs Gender Empowerment Measure, or GEM, evaluates progress in advancing women's standing in political and economic forums. It examines the extent to which women and men are able to actively participate in economic and political life and take part in decision-making. This index is also much more strongly correlated with the HDI than our preferred measure, the GGG, which suggests that the GEM measures the level of female achievement more than the gap between men and women.

\section{Methods}


Our methods are mainly based on graphical representations of the data described above. In Figure 1, we provided a cross-sectional view of fertility and socioeconomic development, and showed that at an HDI level of around 0.80-0.85, the association between TFR and HDI reverses from negative to positive. In the following analyses, we chart the longitudinal patterns in the TFR with respect to the HDI in order to see whether the cross-sectional associations also hold within countries. We first chart the TFR-HDI trajectories for the 30 countries for which longitudinal data were available (Figure 2). We scale the data so that the origin of the horizontal axis corresponds to the reference year in which the HDI is within the 0.80-0.85 range, a range in which the crosssectional plots suggest a reversal of the HDI-TFR association, and the TFR is at its minimum. Countries pass through this origin and the trajectories that end in the top-right quadrant are consistent with the cross-sectional fertility reversal, while the trajectories that end in the bottomright quadrant correspond with a further decline in fertility. Using a similar graphical approach, we then analyze the longitudinal patterns for age-specific fertility in order to determine which age groups are contributing to the reversal in the TFR-HDI association. The last set of graphical analyses describes the association between the completed cohort fertility and the HDI.

We use longitudinal regression approaches to assess the robustness of the basic findings to the timing of fertility, country heterogeneity and period trends. We estimate regression models that control for unobserved heterogeneity and time trends, and account for fertility timing by controlling for the mean age at birth, and use the tempo-adjusted TFR as the dependent variable. We use a panel of 35 countries over the years 1975-2008 (all of the countries and the years for which the data are available), and estimate the effects of the HDI on fertility using the following models:

$$
\operatorname{TFR}_{i, t}=\alpha+\beta_{1} H D I_{i, t}+\beta_{2} H D I_{i, t}^{2}+\gamma_{i}+\theta_{t}+\varepsilon_{i, t},
$$




$$
\begin{aligned}
& \operatorname{TFR}_{i, t}=\alpha+\beta_{1} \mathrm{HDI}_{i, t}+\beta_{2} \mathrm{HDI}_{i, t}^{2}+\gamma_{i}+\theta_{t}+\phi_{1} \Delta M A B_{i, t}+\phi_{2} \Delta \Delta M A B_{i, t}+\varepsilon_{i, t}, \\
& \mathrm{ATFR}_{i, t}=\alpha+\beta_{1} \mathrm{HDI}_{i, t}+\beta_{2} \mathrm{HDI}_{i, t}^{2}+\gamma_{i}+\theta_{t}+\varepsilon_{i, t} .
\end{aligned}
$$

Here $T F R_{i, t}$ and $A T F R_{i, t}$ are the total fertility rate and the tempo-adjusted TFR for country $i$ at time $t$; HDI is the Human Development Index; $\gamma_{i}$ and $\theta_{t}$ are the country and time fixed effects; $\triangle M A B$ and $\triangle \triangle M A B$ are the first and the second difference in the mean age at birth; and $\varepsilon_{i, t}$ is the residual. We bootstrap (10,000 replications) the standard errors. As a robustness check, we estimated the models with country-specific linear time-trends. ${ }^{2}$

The purposes of the three models are as follows. Model 1 estimates the TFR-HDI association and controls for differences in fertility levels across countries through the country fixed effects $\gamma_{i}$, and for shared TFR trends through the period indicators $\theta_{t}$. This model can provide stronger evidence for a causal relationship than cross-sectional analyses because the association is estimated from within-country variation, and unobserved fixed country factors and shared period factors are controlled for.

Model 2 considers whether the TFR-HDI association could be mediated by changes in the timing of fertility, and extends Model 1 by adding controls for first- and second-order differences in the mean ages at birth ( $\triangle M A B$ and $\triangle \triangle M A B$ ). The first difference controls for the initial TFRsuppressing effect when fertility starts moving to older ages, while the second difference controls for the potential TFR increase when postponement slows down. This regression approach is an alternative to using tempo-adjusted fertility, and is useful in a longitudinal analysis in which tempo adjustments tend to increase the variance in the data, or in which data are not available due

\footnotetext{
2 Myrskylä et al. (2009) used a structural break model. Some have criticized the approach by arguing that the technique does not provide an all-in-one estimation of the breakpoint level (Luci and Thevenon 2010). The current paper uses a one-step quadratic model. Others have suggested that the results in Myrskylä et al. (2009) were driven by the inclusion of low-HDI data points (Lauer 2009). Here we exclude all data points that pertain to HDI levels of 0.75 or below.
} 
to limited information on parity-specific fertility. As a robustness check, we also estimated Model 2 with the mean age at first birth; however, in this case the sample size drops to 16 countries.

Models 3 is analogous to Model 1 but uses the tempo-adjusted TFR instead of the standard period TFR as the dependent variable. Thus, the model removes tempo effects directly from the dependent variable, and further tempo adjustments are not needed. This tempo adjustment comes at the cost of sample size, as we have time series of tempo-adjusted fertility for only 16 countries.

After documenting the contribution of tempo effects to the reversal, we analyze the role of gender equality in explaining the variation in the fertility-development association at high levels

of development. Using the trajectories shown in Figure 2, we calculate for each country the slope of fertility with respect to the HDI (defined as change in the TFR divided by change in the HDI since the reference year when the HDI was in the range of 0.80-0-85 and the TFR was at its lowest point), and examine whether the variation in the slopes across countries could be explained by variation in gender equality.

\section{Results}

Age and cohort patterns of the reversal in the fertility-development link

Figure 2 shows the country-specific TFR trajectories with respect to the HDI. Trajectories ending in the top-right quadrant are consistent with the cross-sectional fertility reversal; trajectories ending in the bottom-right quadrant correspond with a further decline of fertility, despite continued advances in development. In most countries, the TFR has increased from the troughs observed when the HDI was in the range 0.80-0.85. While there are exceptions (e.g., Brunei, 
Japan, Switzerland), 22 of the 30 countries end in the top-right quadrant of the figure. The thick line in Figure 2 shows the median TFR trajectory with respect to the HDI, calculated as the median of the country-specific slopes. The median slope at HDI levels up to the reference year 11.0. After the reference year, the median slope is 3.0 , which suggests that a $0.05 \mathrm{HDI}$ increase is associated with a 0.15 TFR increase. ${ }^{3}$

These results confirm that as development has progressed and these 22 countries attained an advanced HDI level of 0.80 or higher, the earlier downward trend in the TFR was reversed. As a result, fertility in 2008 was higher than the minimum that was observed while a country's HDI was within the $0.80-0.85$ interval. For example, US fertility reversed in 1976 (reference year) at an HDI of 0.81 . Since then, fertility has increased from 1.74 to 2.10. In Sweden, the reversal occurred in 1978 at an HDI of 0.81 ; since then, the TFR has increased from 1.60 to 1.91. In Spain, the turning point was in 1995 at an HDI of 0.85, after which the TFR increased from 1.17 to 1.46. Japan, however, exited the HDI region 0.80-0.85 in 1993 with a TFR 1.46, and has since seen its fertility decline to 1.34 .

\section{FIGURE 2 HERE}

Figure 3 shows the longitudinal trajectories of age-specific fertility with HDI. The number of countries in these analyses drops from 30 in Figure 2 to 25 in Figure 3 because the data are not available to us. ${ }^{4}$ The origin of the horizontal axis is located in the same year as in Figure 2. Panel A shows the fertility trajectories for ages below 30, and confirms that in almost all of the countries, the decline in fertility among the younger age groups has continued at high levels of development. Panel B shows fertility trajectories at ages above 30. These are in striking contrast to the findings presented in panel $\mathrm{A}$, and show that fertility above age 30 increases in all of the

\footnotetext{
${ }^{3}$ We prefer the median over the mean as the latter is sensitive to outliers, such as Brunei. The mean trajectory is also positive after the reference year (the mean slope is 1.4).

${ }^{4}$ The excluded countries are Kuwait, Singapore, Brunei, Israel, and Hong Kong.
} 
countries with very high development levels. For some countries, the increase is a continuation of the trend that had begun at lower development levels, while for other countries the increase in fertility with respect to the HDI represents a break from the previous downward trend. The median trajectory suggests that after the reference year, a $0.05 \mathrm{HDI}$ increase is associated with a 0.24 increase in fertility. These longitudinal trajectories confirm that the reversal of the development-fertility link can only be attributed to fertility at ages above 30. The Appendix Figure A.2 shows the cross-sectional association of age-specific fertility and the HDI, and the conclusion is the same.

\section{FIGURE 3 HERE}

Next we analyze the cross-country association between development and cohort fertility. Figure 4 plots cohort fertility for the 1970 birth cohort against the average HDI over the years 1995-2005; i.e., when this cohort was aged 25-35. The analysis uses data for all 29 countries for which the data are available. Figure 4 also shows the fitted quadratic curve of fertility on the HDI. The data points and the fitted curve show that cohort fertility first has a decreasing, and then has an increasing association with development: i.e., cohort fertility is negative up to the HDI level of about $0.80-0.85$, and is positive thereafter. The coefficients for both the HDI and the $\mathrm{HDI}^{\wedge} 2$ are statistically significant $(\mathrm{p}<.05)$. While there is considerable variation in the levels of cohort fertility at high HDI levels—-for example, in the region HDI $>=0.85$ completed fertility ranges from 1.5 for Italy, Germany, Spain, and Japan to above two for Iceland, New Zealand, Ireland, the United States, Norway, and Australia - the HDI still explains an important fraction of the overall variance in cohort fertility among advanced countries $\left(R^{2}=0.21\right)$. Further analysis by age (not shown here) suggests that the positive association between completed cohort fertility and the HDI at high HDI levels is, as was the case for period fertility, attributable to fertility at ages 30 and above. Thus, development and cohort fertility are negatively associated at low to 
moderately high levels of development, but become positively associated at high levels of development.

\section{FIGURE 4 HERE}

Panel regression analyses of the reversal of the development-fertility association

The graphical analyses conducted so far could not fully control for country heterogeneity or time trends. Table 1 shows results of panel regression that analyze the TFR-HDI association and control for these factors as well as for the changes in timing of birth using a panel of 35 countries over the years 1975-2008. Appendix Figure A.3 illustrates the predictions for these regression models.

Model 1 includes controls for time and country fixed effects, and confirms what the graphical analyses suggested. Net of unobserved country heterogeneity and time trends, the TFR declines with development up to an HDI level of $0.80-0.84$, with the predicted minimum being HDI $=0.82$. At higher HDI levels, the association reverses. The coefficients for both the HDI and the $\mathrm{HDI}^{2}$ are significant at the $\mathrm{p}=.001$ level.

When controls for the timing of fertility are introduced (Model 2), the positive association between the TFR and the HDI at high HDI levels attenuates, but the coefficients for the HDI and the $\mathrm{HDI}^{2}$ stay significant $(\mathrm{p}<.01)$. The coefficients for the first and the second differences in the mean age at birth are negative and positive, respectively. This suggests-as is predicted by the tempo-adjustment framework (Kohler and Ortega 2004) — that when the mean age at birth first starts to increase, the TFR is suppressed, but when the change in the mean age at birth slows down, the suppressing effect attenuates. Using alternatively mean age at first birth as a control resulted in the sample size dropping to 16 countries but little change in the TFR-HDI associations (Appendix Figure A.4). 
Model 3 is otherwise analogous to Model 1, but it uses the tempo-adjusted TFR as the dependent variable. The coefficients for both the HDI and the $\mathrm{HDI}^{2}$ continue to be statistically significant $\left(\mathrm{p}^{<.05}\right)$, and the estimated association between the TFR and the HDI continues to be U-shaped, with a minimum TFR obtained at an HDI level of 0.80 .

\section{TABLE 1 HERE}

Thus, each of the three models reproduces the U-shaped TFR-HDI association that has a minimum at approximately the same level as the level that was observed in the graphical analyses. These results confirm that at high levels of development, further increases in the HDI have a positive impact on fertility net of tempo-effects. The positive slope of fertility with respect to the HDI at high HDI levels is, however, flatter when the association is adjusted for tempoeffects. Thus, a portion of the association is attributable, or is perhaps mediated, by tempo effects.

Our models have a parsimonious quadratic specification, which may, however, result in unrealistic predictions at very high HDI levels. A more flexible specification is cubic, which allows for two turning points. We estimated the Models 1-3 with a cubic specification, and each model suggested that the TFR-HDI association changes from negative to positive in the HDI range 0.80-0.85, and that at very high HDI levels (0.90-0.95) the association flattens. For example, for Model 1 the cubic specification predicted that for a HDI increase from 0.825 to 0.875, the TFR increases by $0.21(\mathrm{p}<.05)$, and that for a HDI increase from 0.875 to 0.950 , the TFR increases by $0.02(\mathrm{p}=.94)$.

Gender equality and the reversal of the development-fertility association

Figures 2 and 4 document that, within the general pattern of reversal of the association between development and fertility, there is considerable heterogeneity across countries. Figure 2, for example, shows that the fertility levels of the Scandinavian countries and of the majority of 
Western European countries follow an increasing path after the reference year, while several East Asian, Middle Eastern, and Central European countries have continued to experience fertility declines, despite further increases in development. As we noted earlier, we consider gender equality to be a potential key factor in the increase in fertility as development reaches very high levels. We therefore hypothesize that the pace of the increase in fertility after the HDI has reached the 0.80-0.84 level will be correlated with gender equality, as measured by the Global Gender Gap (GGG) index. The pace of the fertility increase is measured through the longitudinal slope of the TFR as a linear function of the HDI after the reference year (see Figure 2).

Figure 5 plots the pace of the fertility increase against the average GGG in the years 2006-2010 for the 30 countries shown in Figure 3. The reporting year for the GGG measures gender equality two years earlier; thus, the years 2006-2010 reflect gender equality in 2004-2008, the last five years of observation. Figure 5 includes predicted values from a quadratic regression of the pace of fertility increase on the GGG. The figure shows that gender equality is strongly associated with fertility trajectories: at GGG levels below 0.65, all of the countries have a negative pace. At GGG levels below 0.70, only about half of the countries (five out of 11) have a negative pace. At GGG levels of 0.70-0.75 the majority of the countries (eight out of 11 ) have a positive pace. Meanwhile, all eight countries with a GGG above 0.75 have a positive pace. In other words, in countries where gender equality is low, fertility continues to be negatively associated with development; whereas in countries where gender equality is high, we observe a reversal in the development-fertility link.

\section{FIGURE 5 HERE}

We assessed the robustness of this finding in several ways. Some of the association between the GGG and the pace of the fertility increase may be driven by differences in the initial levels of fertility in the reference year. We therefore studied the sensitivity of the association of 
the GGG pace of fertility increase to the fertility level. The results, shown in Appendix Figure A.5 (dashed line), confirm that the positive association is robust to controlling for fertility in the reference year. Second, we assessed whether the association might be confounded by the regional clustering of countries. We assessed the robustness of the positive GGG pace of fertility increase association to clustering by including controls for regions (Scandinavian, Western European, Eastern European, Mediterranean, Asian, English-speaking, or Middle Eastern). The region coefficients were not significant, either individually or jointly (p>.10 for each test), but the predicted shape between the pace of the fertility increase and the GGG continued to be similar to that the shape shown in Figure 5. The association was also robust to the removal of any of the seven regions. We also considered restricting the gender equality-pace of fertility increase analysis to European countries only. This resulted in a significant decrease in the variation of fertility trajectories: when all of the countries were included, the pace of fertility change with respect to the HDI ranged from -15 to seven; when only the European countries were included, this range was from -0.6 to seven. Because of the much narrower degree of variation, there is less room to explain outliers: i.e., almost all of the highly developed European countries have experienced fertility increases with advancing development. Consequently, within European countries the coefficient of the GGG in a regression of the pace of fertility increase is statistically not significant, although it remains positive in sign (results not shown).

We also analyzed the role of gender equality in explaining the U-shaped association between cohort fertility and HDI. We regressed cohort fertility for the 1970 birth cohort on the quadratic average HDI over the years 1995-2005, and compared models which include and which do not include gender equality (GGG). We observed that the controls for the GGG attenuated the positive fertility-HDI association observed at high HDI levels (Appendix Figure A.6), which 
further supports the idea that gender equality is crucial in allowing socioeconomic development to positively influence fertility.

As a final robustness check, we conducted all of the analyses involving the GGG with two alternative measures of gender equality: the UNDP's Gender-related Development Index and the Gender Empowerment Measure. The results changed only little.

\section{Discussion}

The recent discovery of a reversal in the link between socioeconomic development and fertility is important but several key aspects of this reversal have yet been explored, including the demographic mechanisms that have contributed to it and the potential role of gender equality in mediating the reversal. This paper showed that the reversal of the fertility-development association exists when both period- and cohort-based indicators of fertility are used, and that the reversals hold even when using tempo-adjusted indicators of fertility, Our analyses also show that the reversal of the recent fertility-development relationship is primarily driven by increasing fertility in advanced societies at older reproductive ages. We also documented that the reversal is

conditional on gender equality: countries that rank high in development, as measured by health, income, and education, but low in gender equality, continue to experience declining fertility in parallel with development.

Analyses by age and cohort and analyses based on the tempo-adjusted TFR answer the critical tempo question: Is the reversal in the development-fertility association driven by increases of the quantum, or is it only due to changes in the timing of fertility? Our analyses indicated that fertility above age 30 is the key to the reversal of the development-fertility link. Furthermore, regression analyses, which controlled for country heterogeneity and time trends, 
showed that when all ages are combined, the association between the HDI and the TFR is positive at high HDI levels. These results were robust to using tempo-adjusted TFR as the dependent variable. The analysis of the link between development and the fertility of the 1970 birth cohort also showed that for countries in which members of this cohort experienced HDI levels above 0.85 in their prime childbearing years, fertility was higher than in countries in which the cohort experienced fertility rates in the region of $0.80-0.85$ or below. The cohort patterns, and the robustness of the regression results to tempo-adjustments, suggest that the positive association of development with fertility exists net of changes in the timing of fertility. While tempo effects contribute to the reversal, and may even be part of the mediating mechanism, the reversal exists net of the recuperation in the TFR that may result from changes in the timing of fertility.

Exploiting the heterogeneous trajectories of countries that cross the "critical” region of development (in which the HDI was approximately 0.80-0.85), we also investigated the role of gender equality. We showed that the Global Gender Gap index is a useful predictor of whether a country is on a declining or an increasing fertility trajectory after this critical development region is reached. Specifically, our analyses indicated that a relatively high level of gender equality seems to be a precondition for the reversal. The heterogeneity of the advanced countries that rank high in gender equality and experience increasing fertility suggests that the ways in which countries address the problem of combining work and family are context-specific. Nonetheless, our results are useful in identifying the kinds of institutional settings that facilitate the fertility reversal. Earlier research has speculated that a failure to respond to the challenges of development by creating institutions that facilitate work-family balance and gender equality might explain the exceptional pattern found in rich East Asian countries, which continue to be characterized by a negative HDI-fertility relationship. Our analyses support this assumption by showing that the reversal is conditional on gender equality. 
The reversal in the fertility-development association and its mechanism have important implications for future fertility in the developed world. A large number of developed countries have reached the threshold at which the association between socioeconomic development and fertility reverses to positive. These countries may experience fertility increases in the near future, if the positive trend in positive socioeconomic development continues. However, if trends in socioeconomic development stall or become negative-as they have in countries such as Italy, Greece, Slovenia, and Ireland during the most recent recession—our results suggest that these countries could experience fertility declines. Goldstein et al. (2013) analyzed the fertility responses in Europe to this recession, and found that the countries that were hit hardest by the recession have tended to have the most negative fertility responses. In addition, our results suggest that socioeconomic development in itself is not necessary for reversing the fertility trends: the positive impact is conditional on gender equality, and countries that make rapid progress in other dimensions of socioeconomic development, but not in gender equality, are expected to see further declines in fertility.

There are limitations to our analysis. First, it has been speculated that the reversal in the fertility-development association could be driven by migrant populations (Hugh 2009; Parker 2009; Reebs 2009; Yong 2009). However, Sobotka (2008) finds that while immigrants contribute to the total number of births and their share has increased in the last decade, the net effect on the TFR in most European countries has been small. Goldstein et al. (2009) reach similar conclusions in an analysis of seven European countries. For example, in Spain, the fertility of native women increased from 1.12 in 1998 to 1.30 in 2006, while the overall TFR increased from 1.15 to 1.35. Castro Martin and Rosero-Bixby (2011) also found that the contribution of migrant women on Spanish TFR is modest. The small effect of immigration on fertility increases in Europe is partly because many of the migrants come from low-fertility countries. But even in the United States, 
where migrants come from higher fertility regions, the increases in the TFR of the non-Hispanic white population in the 1990s and 2000s until the most recent recession were similar to the overall TFR increase (Martin et al. 2009). It therefore appears that the increases in the TFR among the native-born population are often similar in size to the increases in the TFR for the population as a whole. Our assumption that HDI increases that result in increases in the TFR are attributable to behavioral change-rather than to compositional changes via immigration-is therefore not challenged by recent patterns of immigration to highly developed countries.

Second, due to data limitations, our measures of gender equality were cross-sectional. Gender equality may have different effects on fertility as the economic role of women progresses in societies (McDonald 2000). First, when equality on the labor market increases, fertility may decrease due to the rising opportunity costs of having children. Later, as advanced societies acknowledge the issues that working mothers and couples with children face, increasing gender equality may be pivotal in facilitating the development of institutions and social norms that help women in combining work and family (Mills 2010). Further research might provide insights into these processes through longitudinal analyses of the relationship between gender equality and fertility. Moreover, confounding factors that are associated with both gender equality and fertility may explain some of the influence of gender equality in the development-fertility reversal. Longitudinal analyses would be helpful in assessing the importance of such factors.

Third, our analyses of cohort fertility were based on a single cohort, the 1970 birth cohort. In order to analyze the cohorts who have experienced very high levels of development-i.e., the cohorts born in the 1970s or 1980s—we will need to wait for another decade. Using historical data, however, we documented that the U-shaped association between completed cohort fertility and development is also observed for the 1960 and the 1965 birth cohorts. 
Fourth, our analysis focused on national-level trends and cross-national differences in fertility. These may mask important variations across sub-populations. For example, the patterns may differ by socioeconomic status or educational level. Further insights could be gained from analyses focusing on sub-populations.

Despite these limitations, our results extend and provide additional support for the finding that increases in development are an important factor driving fertility reversals in developed countries. In particular, the results suggest that development contributes to fertility beyond tempo effects, but that the positive impact of development on fertility is conditional on gender equality: countries that rank high in development as measured by health, income, and education, but low in gender equality, continue to experience declining fertility. This finding is consistent with the assumption that work-family balance plays an important role in shaping fertility at older reproductive ages. The development-driven fertility reversal may have important long-run implications, as increasing fertility at the highest levels of socioeconomic development may help decrease the rates of population aging and ameliorate the social challenges that have been associated with low fertility. 


\section{References}

Bongaarts, J. 1998. "Demographic consequences of declining fertility." Science 282:419-420.

Bongaarts, J. 2002. "The End of the Fertility Transition in the Developed World." Population and Development Review 28(3):419-443.

Bongaarts, J.and G. Feeney. 1998. "On the Quantum and Tempo of Fertility." Population and Development Review 24(2):271-291.

Bongaarts, J.and T. Sobotka. 2011. "Demographic Explanations for the Recent Rise in Europe's Fertility." in Population Association of America Annual Meeting. Washington, DC.

Bongaarts, J.and S.C. Watkins. 1996. "Social Interactions and Contemporary Fertility Transitions." Population and Development Review 22(4):639-682.

Bryant, J. 2007. "Theories of Fertility Decline: Evidence from Development Indicators." Population and Development Review 33.

Butler, D. 2004. "The fertility riddle." Nature 432:38-39.

Castro Martin, T.and L. Rosero-Bixby. 2011. "Motherhood and transnational Borders immigrants’ women fertility in Spain." Revista Internacional de Sociologia 69:105-137.

D’Addio, A.and M. D’Ercole. 2005. "Trends and Determinants of Fertility Rates in OECD Countries: The Role of Policies." OECD Social, Employment and Migration Working Papers 27. Paris, OECD.

Esping-Andersen, G. 2009. The Incomplete Revolution: Adapting Welfare States to Women's New Roles. Cambridge, UK: Polity Press. 
European Commission. 2005. "Green Paper “Confronting demographic change: a new solidarity between the generations”." Commission of the European Communities. Brussels.

Eurostat Online Database. 2011. Available at http://epp.eurostat.ec.europa.eu.

Frejka, T.and G. Calot. 2001. "Cohort Reproductive Patterns in Low-Fertility Countries." Population and Development Review 27(1):103-132.

Frejka, T., G.W. Jones, and J.-P. Sardon. 2010. "East Asian Childbearing Patterns and Policy Developments." Population and Development Review 36(3):579-606.

Gauthier, A.H. 2007. "The impact of family policies on fertility in the industrialized countries: a review of the literature." Popul. Res. Policy Rev. 26:323-346.

Goldstein, J., M. Kreyenfeld, A. Jasilioniene, and D.D. Karaman Örsal. 2013. "Fertility Reactions to the "Great Recession" in Europe: Recent Evidence from Order-Specific Data." Demographic Research 29(4):85-104.

Goldstein, J., W. Lutz, and M. Rita Testa. 2003. "The emergence of sub-replacement family size ideals in Europe." Population Research and Policy Review 22:479-496.

Goldstein, J.R., T. Sobotka, and A. Jasilioniene. 2009. "The end of "lowest-low fertility?"." Population and Development Review 35(4):663-699.

Hausmann, R., L.D. Tyson, and S. Zahidi. 2010. "The Global Gender Gap Report 2008." World Economic Forum. Geneva, Switzerland. https://members.weforum.org/pdf/gendergap/report2010.pdf. 
Hugh, E. 2009. "'Advances in development reverse fertility declines” - science or hocus pocus?" in A Fistful of Euros Blog (8 August 2009), http://fistfulofeuros.net/afoe/economics-anddemography/.

Human Fertility Database. 2011. "Human Fertility Database. Max Planck Institute for Demographic Research (Germany) and Vienna Institute of Demography (Austria). Available at www.humanfertility.org

Kohler, H.-P., F.C. Billari, and J.A. Ortega. 2002. "The Emergence of Lowest-Low Fertility in Europe during the 1990s." Population and Development Review 28(4):641-680.

Kohler, H.-P.and J.A. Ortega. 2004. "Old Insights and New Approaches: Fertility Analysis and Tempo Adjustment in the Age-Parity Model. ." Vienna Yearbook of Population Research 2004 2:57-89.

Lauer, M. 2009. "'Is there a baby bounce?" in Stubborn Mule Blog (4 September 2009), http://www.stubbornmule.net/2009/09/baby-bounce/.".

Lee, R.D. 2003. "The demographic transition: three centuries of fundamental change. ." J. Econ. Perspect. 17:167-190.

Luci, A.and O. Thevenon. 2010. "Does economic development drive fertility rebound in OECD countries?" in Population Association of America Annual Meeting. Dallas, TX.

—. 2011. "Do fertility trends respond to family policies in OECD countries?" in Population Association of America Annual Meeting. Washington, D.C.: Population Association of America. 
Lutz, W., B.C. O'Neill, and S. Scherbov. 2003. "Europe's population at a turning point." Science 299:1991-1992

Lutz, W., W. Sanderson, and S. Scherbov. 2008. "The coming acceleration of global population aging." Nature 451:716-719.

Martin, J.A., B.E. Hamilton, P.D. Sutton, S.J. Ventura, M.A. Fay, F. Menacker, S. Kirmeyer, and M.S. Mathews. 2009. "Births: Final data for 2006." Centers for Disease Control. http://www.cdc.gov/nchs/data/nvsr/nvsr57/nvsr57_07.pdf.

McDonald, P. 2000. "Gender Equity in Theories of Fertility Transition." Population and Development Review 26(3):427-439.

McDonald, P. 2006. "Low fertility and the state; the efficacy of policy." Population and Development Review 32(3):401-510.

Mills, M. 2010. "Gender roles, gender (in) equality and fertility: An empirical test of five gender equity indices." Canadian Studies in Population 37:445-474.

Morgan, S.P.and M.G. Taylor. 2006. "Low Fertility at the Turn of the Twenty-First Century." Annual Review of Sociology 32:375-399.

Myrskylä, M., J.R. Goldstein, and Y.-A. Cheng. 2013. "New Cohort Fertility Forecasts for the Developed World: Rises, Falls, and Reversals." Population and Development Review 39(1):3156.

Myrskylä, M., H.-P. Kohler, and F.C. Billari. 2009. "Advances in development reverse fertility declines." Nature 460(7256):741-743. 
Neyer, G.R.and G. Andersson. 2008. "Consequences of family policies on childbearing behavior: effects or artifacts? ." Population and Development Review 34(4):699-724.

OECD. 2011. Doing Better for Families. Paris: OECD Publishing.

Parker, R. 2009. "Fertility decline with rising incomes reverses at high incomes." in FuturePundit Blog (5 August 2009), http://www.futurepundit.com/archives/006423.html.

Preston, S.H., P. Heuveline, and M. Guillot. 2001. Demography: Measuring and Modeling Population Processes. Oxford: Blackwell Publishers.

Reebs, S. 2009. "Birth rates rise in wealthiest nations." in LiveScience Blog (11 October 2009), http://www.livescience.com/culture/091011-population-growth.html.

Rindfuss, R.R., D.K. Guilkey, S.P. Morgan, and Ø. Kravdal. 2010. "Child-Care Availability and Fertility in Norway." Population and Development Review 36(4):725-748.

Ruckdeschel, K. 2009. "Rabenmutter contra Mère Poule: Kinderwunsch und Mutterbild im deutsch-französischen Vergleich." Zeitschrift für Bevölkerungswissenschaft 34(1-2):105-134.

Sobotka, T. 2004. "Is lowest-low fertility explained by the postponement of childbearing?" Population and Development Review 30(2):195-220.

Sobotka, T. 2008. "Overview Chapter 7: The rising importance of migrants for childbearing in Europe." Demographic Research 19(9).

Sobotka, T.and W. Lutz. 2009. "Misleading Policy Messages from the Period TFR: Should We Stop Using It?" European Demographic Research Papers. 4. 
Statistical Yearbook of the Republic of China. 2011. Available at http://eng.stat.gov.tw.

Statistics Australia Online Database. 2010. Available at http://www.abs.gov.au.

Statistics New Zealand Online Database. 2010. Available at http://www.stats.govt.nz.

Statistics Singapore. 2010. "Population Trends 2010”. Available at http://www.singstat.gov.sg.

Thévenon, O. 2011. "Family Policies in OECD Countries: A Comparative Analysis." Population and Development Review 37(1):57-87.

Trovato, F. 2010. "Fertility in Alberta in a Context of Rapid Economic Growth, 1997-2007." Canadian Studies in Population 37(3-4):497-524.

UNDP. 2011. "Statistics of the Human Development Report (UNDP Human Development Report Office, New York, 2011). http://hdr.undp.org/en/statistics/.".

United Nations. 2010. World population policies 2009. New York: Population Division, Department of Economic and Social Affairs.

United nations. 2011. World Population Prospects: The 2010 Revision. new York: united nations, department of economic and Social affairs, Population Division

van Peer, C. 2002. "Desired and achieved fertility." Pp. 117-142 in Dynamics of Fertility and Partnership in Europe: Insights and Lessons from Comparative Research. Volume II. , edited by E. Klijzing and M. Corijn. New York and Geneva: United Nations.

Wilson, C. 2004. "Fertility Below Replacement Level." Science 304:207-208. 
—. 2011. "Understanding Global Demographic Convergence since 1950." Population and Development Review 37(2):375-388.

World Bank. 2010. "World Development Indicators Online Database http://devdata.worldbank.org/dataonline/old-default.htm."

World Economic Forum. 2010. "The Global Gender Gap Report (http://www3.weforum.org/docs/WEF_GenderGap_Report_2010.pdf)."

Yong, E. 2009. "Fertility rates climb back up in the most developed countries." in Not Exactly Rocket Science Blog. http://scienceblogs.com/notrocketscience/2009/08/fertility_rates_climb_back_up_in_the_most_d eveloped_countrie.php. 
TABLES AND FIGURES

Table 1. Panel regression of the total fertility rate (TFR) on the Human Development Index (HDI).

\begin{tabular}{l|lll}
\hline & Model 1 & Model 2 & Model 3 \\
\hline Human Development Index & $-90.7^{\star \star \star}$ & $-63.6^{\star \star \star}$ & $-34.4^{\star}$ \\
Squared Human Development & $55.1^{\star \star \star}$ & $38.2^{\star \star \star}$ & $21.5^{\star}$ \\
Index & & & \\
Mean age at birth, $1^{\text {st }}$ difference & & $-0.84^{\star *}$ & \\
Mean age at birth, 2 & & \\
Country fixed effects & & $0.43^{\star \star}$ & \\
Time fixed effects & $\mathrm{Y}$ & $\mathrm{Y}$ & $\mathrm{Y}$ \\
& $\mathrm{Y}$ & & \\
HDI level at which the model & & & \\
implies a reversal in the HDI-TFR & & & \\
association (-HDI/(2HDI^2) & 0.82 & 0.83 & 0.80 \\
\hline $\mathrm{N}$ & 962 & 962 & 350 \\
Number of countries & 35 & 35 & 16 \\
R2 (within) & 0.41 & 0.48 & 0.27 \\
& & & \\
\hline
\end{tabular}

${ }^{*} \mathrm{p}<.05 * * \mathrm{p}<.01 * * * \mathrm{p}<.001$

Model 1: Panel regression of the TFR on the HDI and the HDI squared, with country and time fixed effects (dummies for each calendar year).

Model 2: Adds first and second differences in the mean age at birth to Model 1.

Model 3: Like Model 1, but uses tempo-adjusted TFR as the dependent variable.

Notes:

(1) Models 1 and 2 include all of the countries for which annual time series are available for the TFR, the HDI, and the mean age at birth, and which have reached the HDI level of 0.75. These 35 countries are: Australia, Austria, Belgium, Bulgaria, Canada, Czech Republic, Denmark, Estonia, Finland, France, Germany, Greece, Hungary, Iceland, Ireland, Italy, Japan, Lithuania, Luxembourg, the Netherlands, New Zealand, Norway, Poland, Portugal, Romania, Russian Federation, Singapore, Slovakia, Slovenia, South Korea, Spain, Sweden, Switzerland, the United Kingdom, the United States.

(1) Model 3 includes all of the countries for which annual time series are available for the tempo-adjusted TFR and the HDI, and which have reached the HDI level of 0.75 . These 16 countries are: Austria, Bulgaria, Canada, Czech Republic, Estonia, Finland, Hungary, Lithuania, the Netherlands, Portugal, Russian Federation, Slovakia, Slovenia, Sweden, Switzerland, the United States. 
Figure 1. Cross-country relationship between the total fertility rate (TFR) and the Human Development Index (HDI); years 1975, 2005 and 2008: Data points and a lowess curve. To prevent the graph from cluttering only the lowess curve is shown for the year 2005.

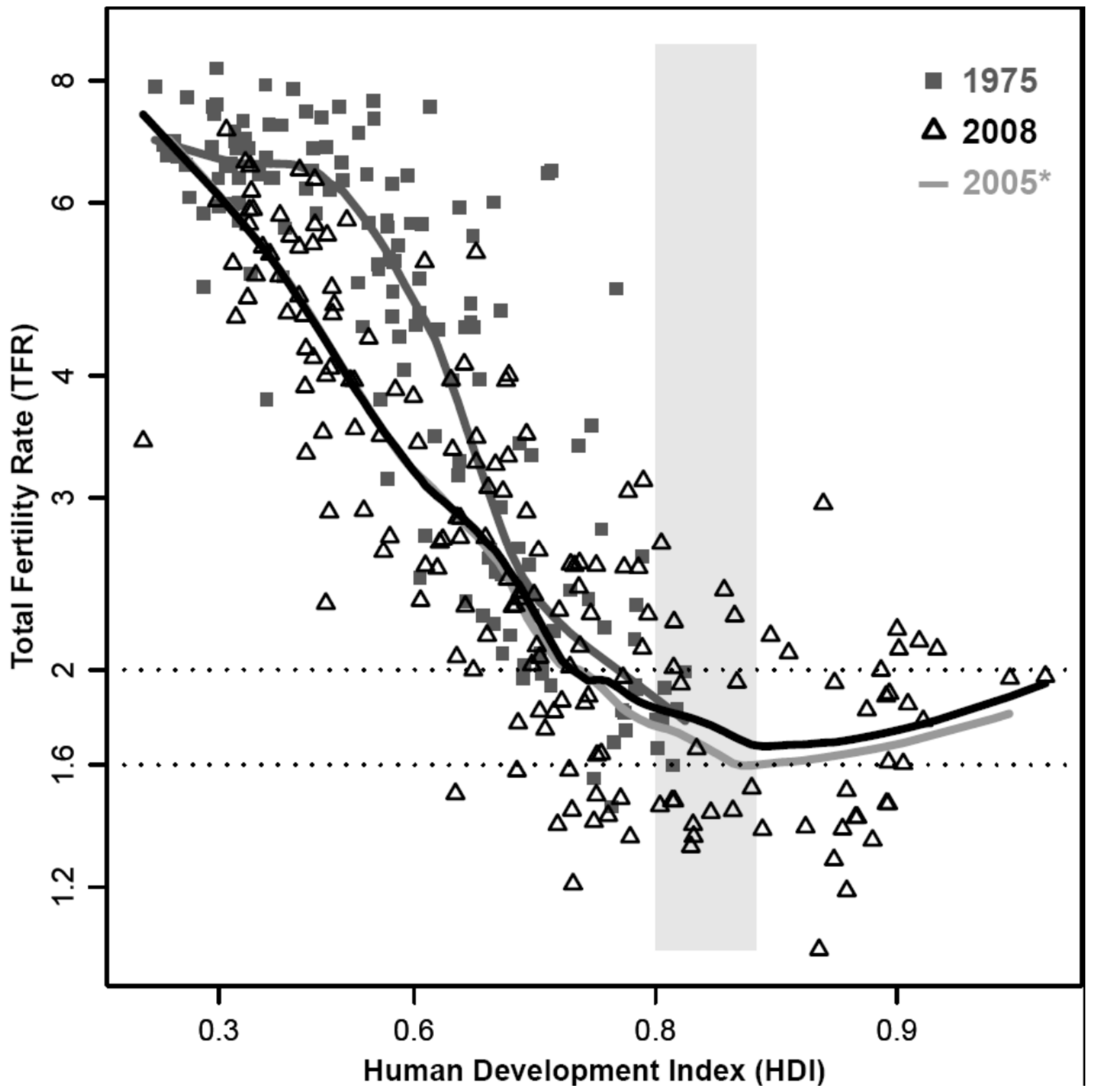

Notes:

(1) Countries with year 2008 HDI in the range 0.80-0.84: Argentina, Chile, Croatia, Czech Republic, Estonia, Hungary, Latvia, Libya, Lithuania, Malta, Poland, Qatar, Slovakia, Uruguay.

(2) Countries with year 2008 HDI >= 0.85: Australia, Austria, Belgium, Brunei, Canada, Denmark, Finland, France, Germany, Greece, Hong Kong, Iceland, Ireland, Israel, Italy, Japan, South Korea, Kuwait, Luxembourg, the Netherlands, New Zealand, Norway, Portugal, Singapore, Slovenia, Spain, Sweden, Switzerland, the United Kingdom, the United States.

(3) We confirmed the significance of the positive TFR-HDI correlation at high HDI levels by calculating the Kendall tau rank correlation between the TFR and the HDI for the year 2008. For the HDI ranges $<0.80,0.80$ 0.84, and $>=0.85$ the correlations were $-0.63(\mathrm{n}=126, \mathrm{p}<.001), 0.01(\mathrm{n}=18, \mathrm{p}>.10)$ and $0.29(\mathrm{n}=30, \mathrm{p}<.05)$, respectively. The correlations were similar for other years. 
(4) The axes are scaled to allow us to focus on developed low to moderate fertility countries, while preserving the less-developed countries in the figure. We use HDI*=-log(1-HDI) and TFR ${ }^{*}=\log (.49 * \mathrm{TFR}) / 31$, where 0.49 and 31 approximate the probability of a newborn being female and the mean age at birth, respectively, so that TFR* approximates the log of the net reproduction rate. While the positive HDI-TFR association at high HDI levels is observed independently of the transformations (Appendix Figure A.1), there are strong conceptual reasons for these levels. An important reason for analyzing the TFR is to assess the effect of fertility on longterm population dynamics. In this context, demographers usually refer to stable population theory, which relates fixed fertility and mortality rates to long-term population dynamics (Preston, Heuveline and Guillot 2001). As differences in the long-term population growth rate are proportional to the log of the TFR, small differences in the TFR have a greater influence in low than in high fertility settings. This is reflected in the log-scaling of the TFR in Figure 1. The HDI scaling is appropriate for emphasizing the differences in the HDI levels among advanced countries that cluster within a relatively narrow HDI range. 
Figure 2. Longitudinal relationship between the total fertility rate (TFR) and the Human Development Index (HDI).

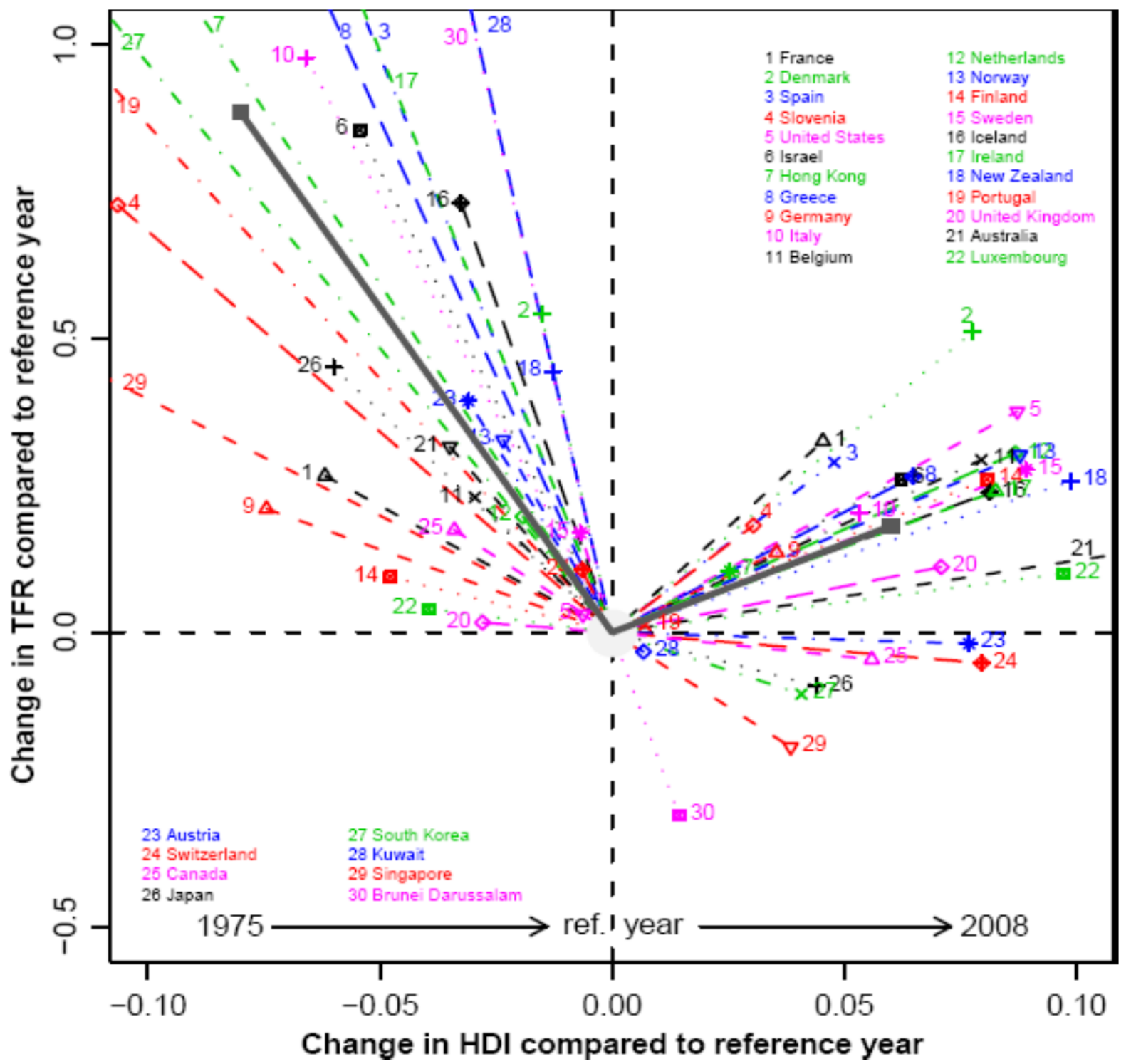

Notes

(1) The figure shows for each country the starting point (which for most countries corresponds to the year 1975; but for a handful of countries the data start later), the critical point in which the country's HDI was in the window 0.80-0.84 and fertility was at its lowest level within this window, and the end point. The starting and the end points are calculated with respect to the critical point. The critical point is scaled to $(0,0)$ on the HDI-TFR plane. The starting point corresponds to the first year of observation, and shows the TFR and HDI difference with respect to the reference year. Correspondingly, the end point is calculated from the last year of observation and shows the TFR and HDI difference with respect to the reference year. The figure includes all of the countries that attained an HDI $>=0.85$ in 2008 and for which longitudinal data on TFR were available. For all of the countries the HDI in 2008 is higher than the HDI in the reference year; for 22 of the 30 countries that attained a HDI $>=0.85$ by 2008, the TFR in 2008 is higher than the TFR in the reference year. The thick gray line is the median of the observed trajectories. 
Figure 3. Longitudinal relationship between fertility by age and the Human Development Index (HDI).
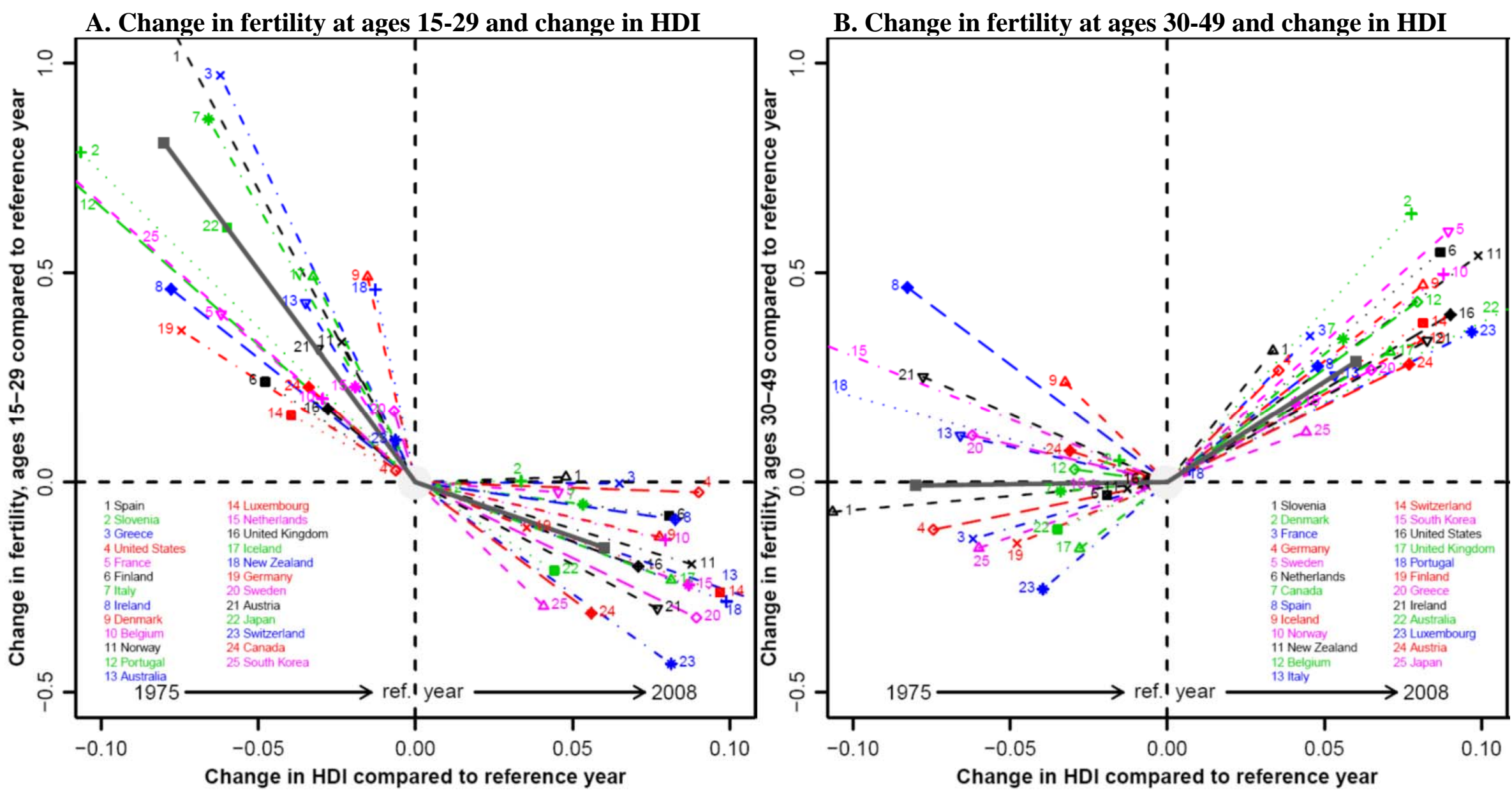

Notes

(1) The figure shows for each country the starting point (which for most countries corresponds to year 1975; but for a handful of countries the data starts later), the critical point at which the country's HDI was in the window 0.85-0.90 and the TFR was at its lowest level within this window, and the end point. The thick gray line is the median of the observed trajectories. 
Figure 4. Completed fertility for the 1970 birth cohort, HDI, and Gender Equality. Data sources: HDI UNDP. Completed cohort fertility: Own calculations based on data sources listed in Table A.1. Global Gender Gap (GGG) index, World Economic Forum.

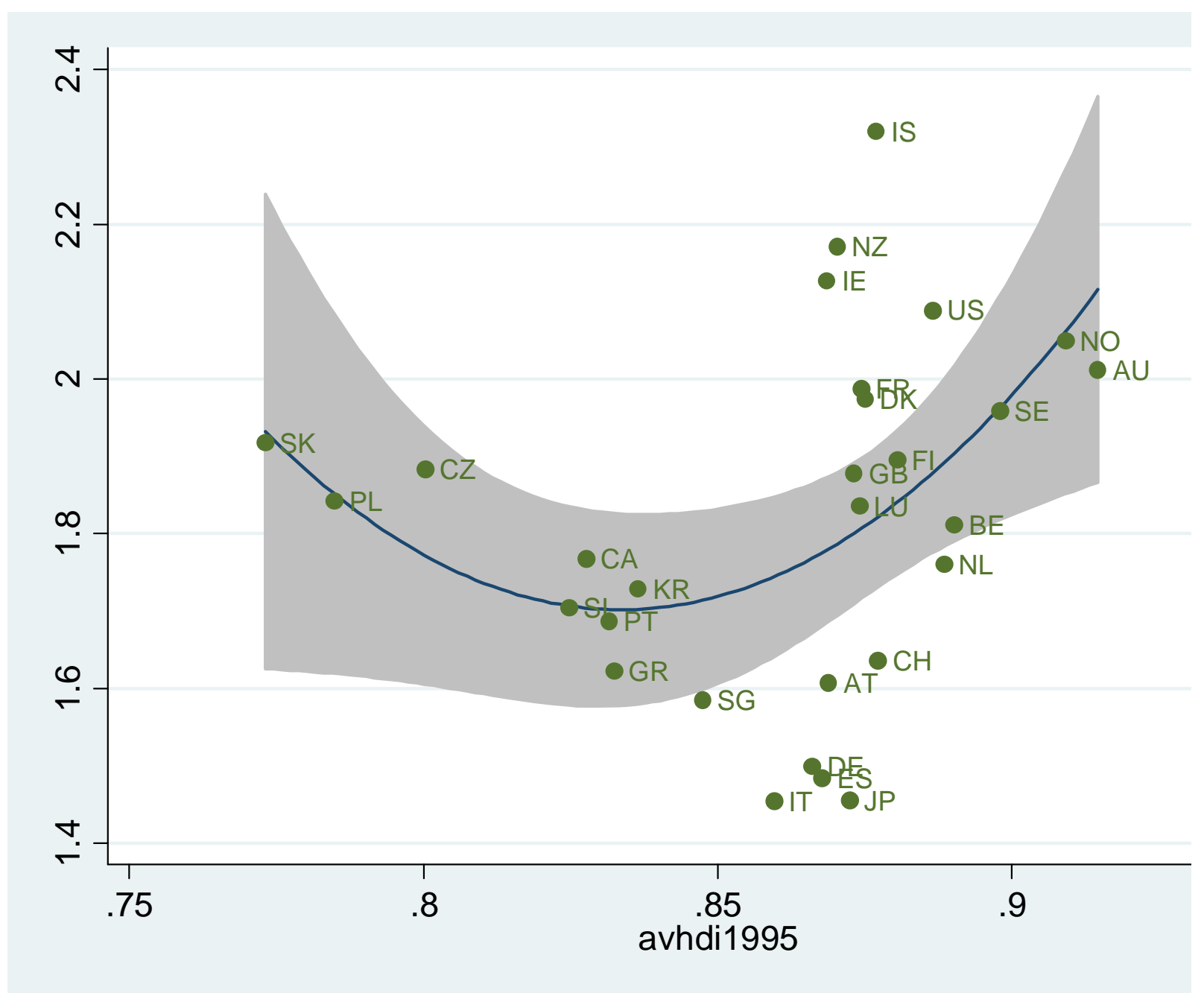

The shaded area is the 95\% confidence interval for the regression of cohort fertility on HDI and squared HDI. Coefficients for both the HDI and the HDI squared are statistically significant $(\mathrm{p}<.05)$; R2 = 0.21.

Notes:

(1) The figure shows the association between completed fertility for the 1970 birth cohort and the average HDI for the years 1995-2005 when the 1970 cohorts were in their prime childbearing years, or aged 25-35.

(2) Cohort fertility is estimated using the simple and conservative "freeze rates" method in which the last observed age-specific rates are extrapolated into the future (Myrskylä et al. 2013).

(3) The countries included are all of the countries for which the relevant data are available (the Gender Equality Index, the HDI, and the fertility rates on an annual basis for single-year age groups from 1985, when the 1970 cohort was aged 15, to 2008). The countries are Slovakia, Poland, Czech Republic, Slovenia, South Korea, Greece, Portugal, Canada, Singapore, Ireland, Italy, Luxembourg, Spain, New Zealand, Iceland, Denmark, Germany, Austria, Finland, Switzerland, Japan, France, Sweden, the United Kingdom, the United States, Belgium, the Netherlands, Norway, Australia, Norway, Australia. 
Figure 5. Pace of TFR increase with respect to HDI (slope) and gender equality. Data sources: Global Gender Gap Index: World Economic Forum. Pace of TFR with respect to HDI: Own calculations based on data from UNDP (HDI) and World Bank Development Indicators and Human Fertility Database (TFR).

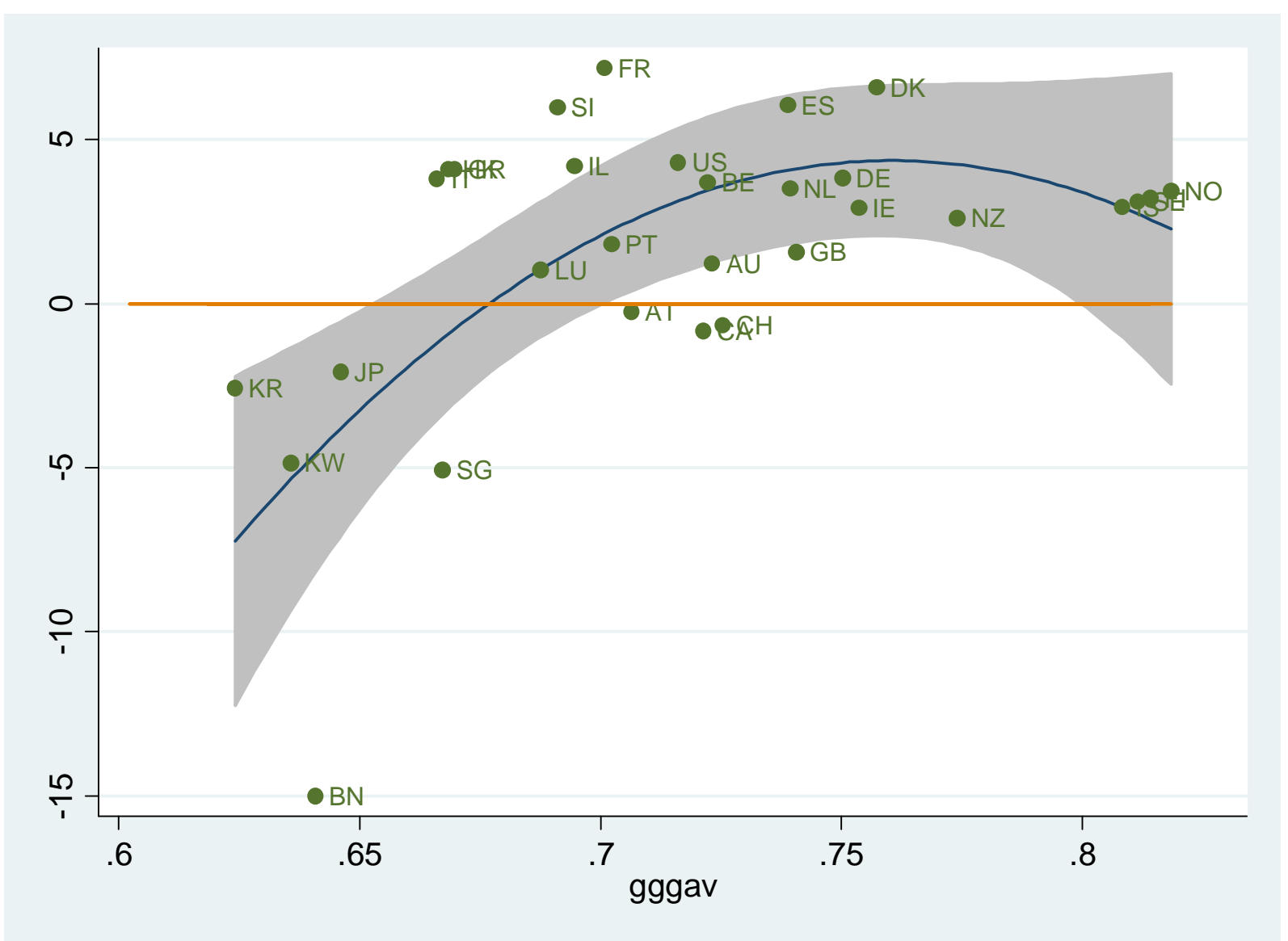

Notes: The shaded areas represent the 95\% confidence interval in the regression of pace of the TFR increase with respect to HDI on GGG and squared GGG. The coefficients for both GGG and GGG squared are statistically significant $(\mathrm{p}<.05) ; \mathrm{R} 2=0.35$.

Notes:

(1) Vertical axis: Pace of TFR with respect to a unit change in HDI at advanced HDI levels.

(2) Horizontal axis: Global Gender Gap (GGG) index averaged over 2006-2010.

(3) Pace of TFR with respect to HDI is calculated as the change in the TFR divided by change in the HDI after the year when the HDI was in the range 0.80-0.84 and the TFR was at its lowest level within this HDI window (see Figure 3 for additional details). 


\section{APPENDIX}

\section{A.1. Data sources}

\section{Total fertility rate (TFR)}

World Bank Development Indicators Online Database (World Bank 2010), http://data.worldbank.org/data-catalog/world-development-indicators

\section{HDI (hybrid Human Development Index)}

United Nations Development Programme (2011), http://hdr.undp.org/en/statistics/hdi/

Completed Fertility Rate (CTFR) for the 1970 birth cohort and Mean Age at Birth (MAB)

Own calculations based on data from the following sources:

Eurostat Online Database (2011), http://epp.eurostat.ec.europa.eu, for Belgium, Bulgaria, Denmark, Estonia, Finland, France, Greece, Hungary, Iceland, Ireland, Italy, Lithuania, Luxembourg, the Netherlands, Poland, Portugal, Romania, Slovenia, Spain, the United Kingdom

Human Fertility Database (2011), http://www.humanfertility.org, for Austria, Canada, Czech Republic, Germany, Norway, Russian Federation, Slovakia, Sweden, Switzerland, the United States

South Korea: Kwang-Hee Jun, Professor of Demography and Sociology, Chungnam National University

Singapore: Statistics Singapore (2010), http://www.singstat.gov.sg

Japan: Ryuichi Kaneko, National Institute of Population and Social Security Research in Japan, and Rikiya Matsukura, Nihon University Population Research for Institute in Japan for

Taiwan: Statistical Yearbook of the Republic of China (2011), http://eng.stat.gov.tw

Australia: Statistics Australia (2010), http://www.abs.gov.au

New Zealand: Statistics New Zealand (2010), http://www.stats.govt.nz

\section{Age-specific fertility (period fertility at ages 15-29 and at ages 30 and above)}

Population Division of the Department of Economic and Social Affairs of the United Nations Secretariat (2009), and the above mentioned sources used for calculating cohort fertility.

\section{Global Gender Gap Index (GGG)}

World Economic Forum (2010), http://www.weforum.org 


\section{A.2. Human Development Index}

United Nations Development Programme (UNDP) occasionally updates the exact definition of the HDI, making comparative and time series analyses challenging. For example, up to 2010 the HDI was calculated as the arithmetic mean of the sub-indexes, but in the 2011 revision the method was changed from arithmetic to geometric means, and some additional changes were made in how the sub-indexes are defined. In conjunction with these changes, the education index changed from being based on literacy and enrollment rates to being based on years of schooling based; and the income index, which was previously based on GDP per capita, has been based on per capita gross national income since the 2011 revision.

The only version of the HDI that is consistently comparable over time and for which the UNDP provides annual time series was introduced alongside the 2011 revision. The UNDP uses this time-consistent HDI in its own trend analyses. For consistency and comparability, we also use this index, even though it deviates slightly from the index used in Myrskylä et al. (2009), in which the authors constructed a longitudinally consistent HDI index from the underlying series of life expectancy, school enrollment, and GDP per capita.

This time-consistent version of the HDI uses the same functional form (geometric mean) as the 2011 revision of the HDI, but it uses as the sub-indexes for health, education, and income the same indicators as those that were in used up to 2010. The time-consistent index is calculated as the geometric mean of (i) the health conditions, as measured by annual life expectancy at birth; (ii) the standard of living, as measured by the logarithm of the annual gross domestic product (GDP) per capita at purchasing power parity (PPP) in US dollars; and (iii) the human capital, as measured by the average of the adult literacy rate and the combined primary, secondary, and tertiary gross school enrolment ratio. This index, which the UNDP terms the hybrid-HDI. but which call the HDI for short, is calculated as the geometric mean of the scaled life expectancy, education, and income 
indexes LE, EI, II as $\left(\mathrm{LE}^{*} \mathrm{EI}^{*} \mathrm{II}\right)^{\wedge} 1 / 3$, where the sub-indexes are obtained as $\mathrm{LE}=(\mathrm{e} 0-20) /(83.166$ 20) and e0 is the period life expectancy at birth; EI $=\left(\mathrm{LIT}^{*} \mathrm{GER}\right)^{\wedge} 1 / 2$, where LIT=(Lit-0)/(99-0) and Lit is the adult literacy rate and GER $=($ Ger-0)/(115.8192-0) and Ger is the combined (primary, secondary, tertiary) gross enrollment ratio; and II = $(\ln (\mathrm{GDP})-\ln (163.28143) /(\ln (106769.74)-$ $\ln (163.28143)$ where GDP is the gross domestic product per capita at purchasing power parity, US $\$ 2,000$.

The time-consistent HDI is calculated using scaling values for each index that are timeinvariant. Thus, the HDI values are comparable over time within each country. This is an important difference with respect to earlier, pre-1999 definitions of the HDI when the scaling values depended on the current minima and maxima. With fixed scaling values, the HDI levels can increase beyond the currently observed highest HDI values as development progresses and the health conditions, the standard of living, and/or the human capital levels further improve. The constant scaling values also imply that countries do not necessarily cluster near a maximum value of one as they reach very advanced development stages. The longitudinal consistency of the HDI enables our analyses to identify if and how within-country changes in development levels during 1975-2008 affect trends in fertility.

The HDI used in this study, the geometric specification of HDI, and the earlier additive specification of the HDI which was used in Myrskylä et al. (2009), are highly similar. The correlations between the time-consistent HDI, the 2011 revision of the HDI, and the earlier arithmetic means-based HDI are 0.98 or higher for each year 1980, 1985, 1990, 1995, 2000, 2005, and 2008 for which the data are published by the UNDP. Thus, it is unlikely that by using an alternative definition of the HDI (which is, in practice, impossible due to the lack of time series data) we would get different results. The main difference between the indexes is that the geometric means-based indexes (both the time-consistent index and the 2011 revision) are on average 0.05 
units lower at high levels of development than the arithmetic means-based index that was used up to 2010 and in Myrskylä et al. (2009). Since Myrskylä et al. (2009) observed that the fertilitydevelopment association reversed from negative to positive in the HDI range of $0.85-0.90$ using the arithmetic means-based HDI, with the time-consistent geometric means-based HDI we expect the reversal to take place at an HDI level that is 0.05 units lower, or in the range of 0.80-0.85. 
Appendix Table A.1. List of countries, their TFR and HDI for the years 1975 and 2008, completed fertility for the 1970 birth cohort, average of the Global Gender Gap (GGG) index for the years 2006-2010, and minimum TFR and the year and HDI for the year the minimum TFR was observed.

\begin{tabular}{|c|c|c|c|c|c|c|c|c|c|c|}
\hline & Country & $\begin{array}{l}\text { TFR } \\
1975\end{array}$ & $\begin{array}{l}\text { TFR } \\
2008\end{array}$ & $\begin{array}{l}\text { HDI } \\
1975\end{array}$ & $\begin{array}{l}\text { HDI } \\
2008\end{array}$ & $\begin{array}{l}\text { Min. } \\
\text { TFR, } \\
1975- \\
2008\end{array}$ & $\begin{array}{l}\text { Year } \\
\text { min. TFR } \\
\text { observed }\end{array}$ & $\begin{array}{l}\text { HDI in } \\
\text { the year } \\
\text { min TFR } \\
\text { observed }\end{array}$ & $\begin{array}{l}\text { Completed } \\
\text { fertility, } \\
1970 \\
\text { cohort }\end{array}$ & $\begin{array}{l}\text { Average } \\
\text { GGG } \\
\text { Index, } \\
2006- \\
2010\end{array}$ \\
\hline 1 & Australia & 2.15 & 1.97 & 0.79 & 0.93 & 1.74 & 2001 & 0.92 & 2.03 & 0.72 \\
\hline 2 & Norway & 1.99 & 1.96 & 0.82 & 0.93 & 1.66 & 1984 & 0.84 & 2.06 & 0.82 \\
\hline 3 & Iceland & 2.61 & 2.14 & 0.79 & 0.91 & 1.93 & 2002 & 0.89 & 2.33 & 0.81 \\
\hline 4 & Ireland & 3.4 & 2.1 & 0.75 & 0.91 & 1.86 & 2005 & 0.9 & 2.15 & 0.75 \\
\hline 5 & Netherlands & 1.66 & 1.78 & 0.8 & 0.91 & 1.47 & 1983 & 0.82 & 1.76 & 0.74 \\
\hline 6 & Canada & 1.82 & 1.6 & 0.81 & 0.9 & 1.49 & 2000 & 0.89 & 1.78 & 0.72 \\
\hline 7 & Denmark & 1.92 & 1.89 & 0.8 & 0.9 & 1.38 & 1983 & 0.82 & 1.98 & 0.76 \\
\hline 8 & Finland & 1.69 & 1.85 & 0.77 & 0.9 & 1.59 & 1987 & 0.82 & 1.9 & 0.81 \\
\hline 9 & France & 1.93 & 2 & 0.79 & 0.9 & 1.65 & 1994 & 0.86 & 2 & 0.7 \\
\hline 10 & Luxembourg & 1.55 & 1.61 & 0.76 & 0.9 & 1.38 & 1985 & 0.79 & 1.85 & 0.69 \\
\hline 11 & New Zealand & 2.33 & 2.2 & 0.79 & 0.9 & 1.9 & 2002 & 0.88 & 2.18 & 0.77 \\
\hline 12 & Spain & 2.79 & 1.46 & 0.77 & 0.9 & 1.15 & 1997 & 0.86 & 1.5 & 0.74 \\
\hline 13 & Sweden & 1.78 & 1.91 & 0.8 & 0.9 & 1.5 & 1999 & 0.91 & 1.97 & 0.81 \\
\hline 14 & Switzerland & 1.6 & 1.48 & 0.81 & 0.9 & 1.4 & 2002 & 0.88 & 1.65 & 0.73 \\
\hline 15 & United States & 1.77 & 2.1 & 0.8 & 0.9 & 1.74 & 1976 & 0.81 & 2.1 & 0.72 \\
\hline 16 & Austria & 1.82 & 1.41 & 0.78 & 0.89 & 1.33 & 2001 & 0.88 & 1.61 & 0.71 \\
\hline 17 & Belgium & 1.74 & 1.82 & 0.78 & 0.89 & 1.49 & 1985 & 0.81 & 1.83 & 0.72 \\
\hline 18 & Italy & 2.21 & 1.41 & 0.77 & 0.89 & 1.18 & 1995 & 0.83 & 1.47 & 0.67 \\
\hline 19 & Japan & 1.91 & 1.34 & 0.79 & 0.89 & 1.26 & 2005 & 0.89 & 1.47 & 0.65 \\
\hline 20 & Germany & 1.45 & 1.38 & 0.77 & 0.88 & 1.24 & 1994 & 0.85 & 1.51 & 0.75 \\
\hline 21 & Greece & 2.37 & 1.51 & 0.76 & 0.88 & 1.25 & 2001 & 0.84 & 1.63 & 0.67 \\
\hline 22 & Israel & 3.55 & 2.96 & 0.76 & 0.88 & 2.7 & 1992 & 0.81 & & 0.69 \\
\hline 23 & Singapore & 2.08 & 1.28 & 0.69 & 0.88 & 1.26 & 2005 & 0.87 & 1.59 & 0.67 \\
\hline 24 & South Korea & 3.47 & 1.19 & 0.62 & 0.88 & 1.08 & 2005 & 0.87 & 1.73 & 0.62 \\
\hline 25 & United Kingdom & 1.81 & 1.94 & 0.78 & 0.88 & 1.63 & 2001 & 0.87 & 1.89 & 0.74 \\
\hline 26 & Hong Kong & 2.67 & 1.04 & 0.7 & 0.87 & 0.9 & 2003 & 0.86 & & 0.67 \\
\hline 27 & Slovenia & 2.2 & 1.53 & 0.73 & 0.87 & 1.2 & 2001 & 0.84 & 1.71 & 0.69 \\
\hline 28 & Brunei Darussalam & 4.9 & 2.08 & 0.78 & 0.86 & 2.08 & 2008 & 0.86 & & 0.64 \\
\hline 29 & Kuwait & 6.44 & 2.17 & 0.73 & 0.86 & 2.17 & 2008 & 0.86 & & 0.64 \\
\hline 30 & Cyprus & 2.35 & 1.52 & 0.66 & 0.85 & 1.51 & 2008 & 0.85 & & 0.66 \\
\hline 31 & Portugal & 2.52 & 1.37 & 0.68 & 0.85 & 1.33 & 2007 & 0.85 & 1.69 & 0.7 \\
\hline 32 & Antig. and Barbuda & 2.43 & & & 0.84 & 1.7 & 2002 & 0.79 & & \\
\hline 33 & Bahrain & 5.56 & 2.27 & 0.66 & 0.84 & 2.27 & 2008 & 0.84 & & 0.6 \\
\hline 34 & Czech Republic & 2.43 & 1.5 & 0.74 & 0.84 & 1.14 & 1999 & 0.79 & 1.89 & 0.68 \\
\hline 35 & Qatar & 6.47 & 2.41 & 0.73 & 0.84 & 2.41 & 2008 & 0.84 & & \\
\hline 36 & United Arab Emir. & 6.01 & 1.94 & 0.68 & 0.84 & 1.94 & 2008 & 0.84 & & 0.62 \\
\hline 37 & Malta & 2.27 & 1.43 & 0.67 & 0.83 & 1.37 & 2007 & 0.83 & & \\
\hline 38 & Estonia & 2.08 & 1.66 & 0.72 & 0.82 & 1.21 & 1998 & 0.76 & 1.87 & \\
\hline 39 & Hungary & 2.35 & 1.35 & 0.71 & 0.82 & 1.27 & 2003 & 0.8 & 1.88 & \\
\hline 40 & Poland & 2.27 & 1.39 & 0.72 & 0.82 & 1.22 & 2003 & 0.8 & 1.84 & \\
\hline
\end{tabular}


Appendix Table A.1, continued.

\begin{tabular}{|c|c|c|c|c|c|c|c|c|c|c|}
\hline & Country & $\begin{array}{l}\text { TFR } \\
1975\end{array}$ & $\begin{array}{l}\text { TFR } \\
2008\end{array}$ & $\begin{array}{l}\text { HDI } \\
1975\end{array}$ & $\begin{array}{l}\text { HDI } \\
2008\end{array}$ & $\begin{array}{l}\text { Minimum } \\
\text { TFR, } \\
1975- \\
2008\end{array}$ & $\begin{array}{l}\text { Year } \\
\text { min. TFR } \\
\text { observed }\end{array}$ & $\begin{array}{l}\text { HDI in } \\
\text { the year } \\
\text { min TFR } \\
\text { observed }\end{array}$ & $\begin{array}{l}\text { Completed } \\
\text { fertility, } \\
1970 \\
\text { cohort }\end{array}$ & $\begin{array}{l}\text { Average } \\
\text { GGG } \\
\text { Index, } \\
2006- \\
2010\end{array}$ \\
\hline 41 & Slovakia & 2.56 & 1.32 & 0.71 & 0.82 & 1.18 & 2002 & 0.78 & 1.92 & \\
\hline 42 & Argentina & 3.32 & 2.24 & 0.71 & 0.81 & 2.24 & 2008 & 0.81 & & \\
\hline 43 & Chile & 3.16 & 1.93 & 0.65 & 0.81 & 1.93 & 2008 & 0.81 & & \\
\hline 44 & Croatia & 2 & 1.47 & 0.72 & 0.81 & 1.33 & 2003 & 0.78 & & \\
\hline 45 & Lithuania & 2.19 & 1.47 & 0.73 & 0.81 & 1.24 & 2002 & 0.78 & 1.76 & \\
\hline 46 & Uruguay & 2.93 & 2.01 & 0.69 & 0.81 & 2.01 & 2008 & 0.81 & & \\
\hline 47 & Latvia & 1.96 & 1.45 & 0.71 & 0.8 & 1.09 & 1998 & 0.72 & & \\
\hline 48 & Libya & 7.51 & 2.7 & 0.62 & 0.8 & 2.69 & 2008 & 0.8 & & \\
\hline 49 & Seychelles & & 2.28 & 0.69 & 0.8 & 1.98 & 2001 & 0.79 & & \\
\hline 50 & Mexico & 5.93 & 2.1 & 0.65 & 0.79 & 2.1 & 2008 & 0.79 & & \\
\hline 51 & Saudi Arabia & 7.31 & 3.12 & 0.55 & 0.79 & 3.12 & 2008 & 0.79 & & \\
\hline 52 & Venezuela & 4.66 & 2.54 & 0.69 & 0.79 & 2.54 & 2008 & 0.79 & & \\
\hline 53 & Bulgaria & 2.23 & 1.48 & 0.68 & 0.78 & 1.09 & 1997 & 0.72 & 1.66 & \\
\hline 54 & Costa Rica & 3.97 & 1.96 & 0.67 & 0.78 & 1.96 & 2008 & 0.78 & & \\
\hline 55 & Oman & 7.2 & 3.05 & 0.42 & 0.78 & 3.05 & 2008 & 0.78 & & \\
\hline 56 & Panama & 4.48 & 2.55 & 0.66 & 0.78 & 2.55 & 2008 & 0.78 & & \\
\hline 57 & Romania & 2.6 & 1.35 & 0.68 & 0.78 & 1.26 & 2002 & 0.73 & 1.62 & \\
\hline 58 & $\begin{array}{l}\text { Saint Kitts and } \\
\text { Nev. }\end{array}$ & & & & 0.78 & 2.11 & 2002 & 0.76 & & \\
\hline 59 & Belarus & 2.17 & 1.42 & 0.7 & 0.77 & 1.2 & 2004 & 0.74 & & \\
\hline 60 & Montenegro & 2.38 & 1.64 & & 0.77 & 1.64 & 2008 & 0.77 & & \\
\hline 61 & Brazil & 4.5 & 1.88 & 0.6 & 0.76 & 1.88 & 2008 & 0.76 & & \\
\hline 62 & Dominica & & & & 0.76 & 1.9 & 2003 & 0.74 & & \\
\hline 63 & Grenada & 4.44 & 2.28 & & 0.76 & 2.28 & 2008 & 0.76 & & \\
\hline 64 & Lebanon & 4.54 & 1.85 & 0.66 & 0.76 & 1.85 & 2008 & 0.76 & & \\
\hline 65 & Malaysia & 4.59 & 2.56 & 0.57 & 0.76 & 2.56 & 2008 & 0.76 & & \\
\hline 66 & $\begin{array}{l}\text { Russian } \\
\text { Federation }\end{array}$ & 1.98 & 1.49 & 0.72 & 0.76 & 1.17 & 1999 & 0.72 & 1.6 & \\
\hline 67 & Serbia & & 1.4 & & 0.76 & 1.4 & 2008 & 0.76 & & \\
\hline 68 & Trinidad and Tob. & 3.41 & 1.64 & 0.7 & 0.76 & 1.6 & 2004 & 0.75 & & \\
\hline 69 & Bosnia and Herz. & 2.41 & 1.21 & & 0.75 & 1.21 & 2008 & 0.75 & & \\
\hline 70 & Colombia & 4.63 & 2.43 & 0.61 & 0.75 & 2.43 & 2008 & 0.75 & & \\
\hline 71 & Ecuador & 5.72 & 2.56 & 0.6 & 0.75 & 2.56 & 2008 & 0.75 & & \\
\hline 72 & Macedonia & 2.65 & 1.44 & 0.68 & 0.75 & 1.44 & 2008 & 0.75 & & \\
\hline 73 & Peru & 5.7 & 2.57 & 0.61 & 0.75 & 2.57 & 2008 & 0.75 & & \\
\hline 74 & Turkey & 5.13 & 2.11 & 0.56 & 0.75 & 2.11 & 2008 & 0.75 & & \\
\hline 75 & Albania & 4.45 & 1.86 & 0.63 & 0.74 & 1.86 & 2008 & 0.74 & & \\
\hline 76 & Azerbaijan & 3.95 & 2.3 & 0.64 & 0.74 & 1.8 & 2002 & 0.65 & & \\
\hline 77 & Kazakhstan & 3.27 & 2.56 & 0.65 & 0.74 & 1.7 & 1999 & 0.67 & & \\
\hline 78 & Mauritius & 3.14 & 1.58 & 0.57 & 0.74 & 1.58 & 2008 & 0.74 & & \\
\hline 79 & Saint Lucia & & 2.01 & & 0.74 & 2 & 2000 & 0.73 & & \\
\hline 80 & Ukraine & 2.02 & 1.39 & 0.71 & 0.74 & 1.1 & 2002 & 0.7 & & \\
\hline 81 & Armenia & 2.75 & 1.74 & 0.61 & 0.73 & 1.68 & 2001 & 0.66 & & \\
\hline 82 & Iran & 6.41 & 1.81 & 0.54 & 0.73 & 1.81 & 2008 & 0.73 & & \\
\hline 83 & $\begin{array}{l}\text { Dominican } \\
\text { Republic }\end{array}$ & 5.19 & 2.65 & 0.56 & 0.72 & 2.65 & 2008 & 0.72 & & \\
\hline 84 & Jamaica & 4.48 & 2.39 & 0.65 & 0.72 & 2.39 & 2008 & 0.72 & & \\
\hline 85 & $\begin{array}{l}\text { Saint Vincent and } \\
\text { the Gren. }\end{array}$ & 4.97 & 2.12 & 0.53 & 0.72 & 2.12 & 2008 & 0.72 & & \\
\hline
\end{tabular}


Appendix Table A.1, continued.

\begin{tabular}{|c|c|c|c|c|c|c|c|c|c|c|}
\hline & Country & $\begin{array}{l}\text { TFR } \\
1975\end{array}$ & $\begin{array}{l}\text { TFR } \\
2008\end{array}$ & $\begin{array}{l}\text { HDI } \\
1975\end{array}$ & $\begin{array}{l}\text { HDI } \\
2008\end{array}$ & $\begin{array}{l}\text { Minimum } \\
\text { TFR, } \\
1975- \\
2008\end{array}$ & $\begin{array}{l}\text { Year } \\
\text { min. TFR } \\
\text { observed }\end{array}$ & $\begin{array}{l}\text { HDI in } \\
\text { the year } \\
\text { min TFR } \\
\text { observed }\end{array}$ & $\begin{array}{l}\text { Completed } \\
\text { fertility, } \\
1970 \\
\text { cohort }\end{array}$ & $\begin{array}{l}\text { Average } \\
\text { GGG } \\
\text { Index, } \\
2006- \\
2010 \\
\end{array}$ \\
\hline 86 & Thailand & 4.49 & 1.82 & 0.54 & 0.72 & 1.8 & 2004 & 0.71 & & \\
\hline 87 & Tunisia & 5.86 & 2.06 & 0.47 & 0.72 & 2 & 2002 & 0.69 & & \\
\hline 88 & Belize & 6.28 & 2.9 & 0.57 & 0.71 & 2.9 & 2008 & 0.71 & & \\
\hline 89 & Jordan & 7.62 & 3.49 & 0.55 & 0.71 & 3.49 & 2008 & 0.71 & & \\
\hline 90 & Maldives & 7.02 & 2.02 & & 0.71 & 2.02 & 2008 & 0.71 & & \\
\hline 91 & Suriname & 4.74 & 2.4 & 0.66 & 0.71 & 2.4 & 2008 & 0.71 & & \\
\hline 92 & Algeria & 7.33 & 2.36 & 0.48 & 0.7 & 2.36 & 2008 & 0.7 & & \\
\hline 93 & China & 3.78 & 1.77 & 0.39 & 0.7 & 1.76 & 2003 & 0.66 & & \\
\hline 94 & El Salvador & 5.72 & 2.32 & 0.54 & 0.7 & 2.32 & 2008 & 0.7 & & \\
\hline 95 & Georgia & 2.5 & 1.58 & 0.69 & 0.7 & 1.57 & 2005 & 0.69 & & \\
\hline 96 & Sri Lanka & 3.78 & 2.33 & 0.56 & 0.7 & 2.19 & 1998 & 0.65 & & \\
\hline 97 & Tonga & 5.43 & 4 & 0.58 & 0.7 & 4 & 2008 & 0.7 & & \\
\hline 98 & Gabon & 5.02 & 3.31 & 0.61 & 0.69 & 3.31 & 2008 & 0.69 & & \\
\hline 99 & Paraguay & 5.22 & 3.05 & 0.58 & 0.69 & 3.05 & 2008 & 0.69 & & \\
\hline 100 & Samoa & 5.24 & 3.95 & 0.58 & 0.69 & 3.95 & 2008 & 0.69 & & \\
\hline 101 & Turkmenistan & 5.78 & 2.48 & & 0.69 & 2.47 & 2008 & 0.69 & & \\
\hline 102 & Indonesia & 5.04 & 2.17 & 0.42 & 0.68 & 2.17 & 2008 & 0.68 & & \\
\hline 103 & Philippines & 5.75 & 3.08 & 0.57 & 0.68 & 3.08 & 2008 & 0.68 & & \\
\hline 104 & Syria & 7.51 & 3.25 & 0.5 & 0.68 & 3.24 & 2008 & 0.68 & & \\
\hline 105 & Bolivia & 6.18 & 3.46 & 0.49 & 0.67 & 3.46 & 2008 & 0.67 & & \\
\hline 106 & Equatorial Guinea & 5.67 & 5.34 & & 0.67 & 5.34 & 2008 & 0.67 & & \\
\hline 107 & Fiji & 4.05 & 2.73 & 0.59 & 0.67 & 2.73 & 2008 & 0.67 & & \\
\hline 108 & Honduras & 6.84 & 3.26 & 0.49 & 0.67 & 3.26 & 2008 & 0.67 & & \\
\hline 109 & Mongolia & 7.07 & 2 & 0.53 & 0.66 & 2 & 2008 & 0.66 & & \\
\hline 110 & Botswana & 6.48 & 2.87 & 0.46 & 0.65 & 2.87 & 2008 & 0.65 & & \\
\hline 111 & Cape Verde & 6.93 & 2.73 & & 0.65 & 2.73 & 2008 & 0.65 & & \\
\hline 112 & Egypt & 5.65 & 2.86 & 0.42 & 0.65 & 2.86 & 2008 & 0.65 & & \\
\hline 113 & Guatemala & 6.2 & 4.11 & 0.45 & 0.65 & 4.11 & 2008 & 0.65 & & \\
\hline 114 & Guyana & 4.38 & 2.32 & 0.58 & 0.65 & 2.32 & 2008 & 0.65 & & \\
\hline 115 & Vietnam & 6.36 & 2.06 & 0.4 & 0.65 & 2.06 & 2008 & 0.65 & & \\
\hline 116 & Moldova & 2.48 & 1.5 & 0.61 & 0.64 & 1.48 & 2005 & 0.63 & & \\
\hline 117 & Namibia & 6.65 & 3.36 & & 0.64 & 3.36 & 2008 & 0.64 & & \\
\hline 118 & Vanuatu & 5.93 & 3.96 & & 0.64 & 3.96 & 2008 & 0.64 & & \\
\hline 119 & Kyrgyzstan & 4.87 & 2.7 & 0.57 & 0.63 & 2.4 & 2001 & 0.6 & & \\
\hline 120 & Nicaragua & 6.6 & 2.72 & 0.51 & 0.63 & 2.72 & 2008 & 0.63 & & \\
\hline 121 & South Africa & 5.25 & 2.54 & 0.57 & 0.63 & 2.54 & 2008 & 0.63 & & \\
\hline 122 & Morocco & 6.42 & 2.35 & 0.38 & 0.61 & 2.35 & 2008 & 0.61 & & \\
\hline 123 & Uzbekistan & 5.67 & 2.56 & 0.57 & 0.61 & 2.36 & 2005 & 0.61 & & \\
\hline 124 & Yemen & 8.71 & 5.22 & & 0.61 & 5.22 & 2008 & 0.61 & & \\
\hline 125 & $\begin{array}{l}\text { Sao Tome and } \\
\text { Principe }\end{array}$ & 6.54 & 3.81 & & 0.6 & 3.81 & 2008 & 0.6 & & \\
\hline 126 & Tajikistan & 6.4 & 3.41 & 0.59 & 0.6 & 3.41 & 2008 & 0.6 & & \\
\hline 127 & Solomon Islands & 7.24 & 3.87 & & 0.58 & 3.87 & 2008 & 0.58 & & \\
\hline 128 & India & 5.08 & 2.74 & 0.36 & 0.57 & 2.74 & 2008 & 0.57 & & \\
\hline 129 & Bhutan & 6.69 & 2.64 & & 0.56 & 2.64 & 2008 & 0.56 & & \\
\hline 130 & Lao & 5.98 & 3.47 & 0.33 & 0.56 & 3.47 & 2008 & 0.56 & & \\
\hline
\end{tabular}


Appendix Table A.1, continued.

\begin{tabular}{|c|c|c|c|c|c|c|c|c|c|c|}
\hline & Country & $\begin{array}{l}\text { TFR } \\
1975\end{array}$ & $\begin{array}{l}\text { TFR } \\
2008\end{array}$ & $\begin{array}{l}\text { HDI } \\
1975\end{array}$ & $\begin{array}{l}\text { HDI } \\
2008\end{array}$ & $\begin{array}{l}\text { Minimum } \\
\text { TFR, } \\
1975- \\
2008\end{array}$ & $\begin{array}{l}\text { Year } \\
\text { min. TFR } \\
\text { observed }\end{array}$ & $\begin{array}{l}\text { HDI in } \\
\text { the year } \\
\text { min TFR } \\
\text { observed }\end{array}$ & $\begin{array}{l}\text { Completed } \\
\text { fertility, } \\
1970 \\
\text { cohort }\end{array}$ & $\begin{array}{l}\text { Average } \\
\text { GGG } \\
\text { Index, } \\
2006- \\
2010 \\
\end{array}$ \\
\hline 131 & Cambodia & 4.93 & 2.91 & 0.27 & 0.54 & 2.91 & 2008 & 0.54 & & \\
\hline 132 & Congo & 6.33 & 4.37 & 0.51 & 0.54 & 4.37 & 2008 & 0.54 & & \\
\hline 133 & Swaziland & 6.82 & 3.53 & 0.47 & 0.53 & 3.53 & 2008 & 0.53 & & \\
\hline 134 & Comoros & 7.05 & 3.95 & & 0.52 & 3.95 & 2008 & 0.52 & & \\
\hline 135 & Pakistan & 6.93 & 3.96 & 0.33 & 0.52 & 3.95 & 2008 & 0.52 & & \\
\hline 136 & Angola & 7.19 & 5.76 & & 0.51 & 5.76 & 2008 & 0.51 & & \\
\hline 137 & Madagascar & 7.22 & 4.72 & 0.39 & 0.5 & 4.72 & 2008 & 0.5 & & \\
\hline 138 & Cameroon & 6.37 & 4.62 & 0.4 & 0.49 & 4.62 & 2008 & 0.49 & & \\
\hline 139 & Kenya & 7.84 & 4.92 & 0.43 & 0.49 & 4.92 & 2008 & 0.49 & & \\
\hline 140 & Nepal & 6.08 & 2.9 & 0.24 & 0.49 & 2.9 & 2008 & 0.49 & & \\
\hline 141 & $\begin{array}{l}\text { Papua New } \\
\text { Guinea }\end{array}$ & 6 & 4.07 & 0.34 & 0.49 & 4.07 & 2008 & 0.49 & & \\
\hline 142 & Tanzania & 6.75 & 5.56 & & 0.49 & 5.56 & 2008 & 0.49 & & \\
\hline 143 & Bangladesh & 6.8 & 2.34 & 0.29 & 0.48 & 2.34 & 2008 & 0.48 & & \\
\hline 144 & Ghana & 6.82 & 4 & 0.36 & 0.48 & 4 & 2008 & 0.48 & & \\
\hline 145 & Haiti & 5.64 & 3.5 & & 0.48 & 3.5 & 2008 & 0.48 & & \\
\hline 146 & Benin & 6.84 & 5.45 & 0.28 & 0.47 & 5.45 & 2008 & 0.47 & & \\
\hline 147 & Mauritania & 6.68 & 4.47 & 0.39 & 0.47 & 4.47 & 2008 & & & \\
\hline 148 & Nigeria & 6.82 & 5.7 & 0.33 & 0.47 & 5.7 & 2008 & 0.47 & & \\
\hline 149 & Sudan & 6.57 & 4.17 & 0.32 & 0.47 & 4.17 & 2008 & 0.47 & & \\
\hline 150 & Uganda & 7.1 & 6.34 & 0.33 & 0.47 & 6.34 & 2008 & 0.47 & & \\
\hline 151 & Côte d'Ivoire & 7.92 & 4.6 & 0.39 & 0.45 & 4.6 & 2008 & 0.45 & & \\
\hline 152 & Djibouti & 6.99 & 3.9 & 0.35 & 0.45 & 3.9 & 2008 & 0.45 & & \\
\hline 153 & Lesotho & 5.76 & 3.33 & 0.34 & 0.45 & 3.33 & 2008 & 0.45 & & \\
\hline 154 & Togo & 7.28 & 4.26 & 0.35 & 0.45 & 4.26 & 2008 & 0.45 & & \\
\hline 155 & Rwanda & 8.23 & 5.41 & 0.29 & 0.44 & 5.41 & 2008 & 0.44 & & \\
\hline 156 & Senegal & 7.56 & 4.82 & 0.29 & 0.44 & 4.82 & 2008 & 0.44 & & \\
\hline 157 & Timor-Leste & 5.15 & 6.48 & & 0.44 & 4.56 & 1978 & & & \\
\hline 158 & Malawi & 7.53 & 5.55 & 0.29 & 0.43 & 5.55 & 2008 & 0.43 & & \\
\hline 159 & Eritrea & 6.5 & 4.63 & & 0.42 & 4.63 & 2008 & 0.42 & & \\
\hline 160 & Gambia & 6.35 & 5.05 & 0.3 & 0.41 & 5.05 & 2008 & 0.41 & & \\
\hline 161 & Zambia & 7.44 & 5.83 & 0.46 & 0.41 & 5.83 & 2008 & 0.41 & & \\
\hline 162 & Ethiopia & 6.77 & 5.32 & 0.21 & 0.4 & 5.32 & 2008 & 0.4 & & \\
\hline 163 & Guinea & 6.88 & 5.41 & & 0.38 & 5.41 & 2008 & 0.38 & & \\
\hline 164 & Burkina Faso & 6.87 & 5.91 & 0.18 & 0.37 & 5.91 & 2008 & 0.37 & & \\
\hline 165 & Mozambique & 6.55 & 5.06 & 0.23 & 0.37 & 5.06 & 2008 & 0.37 & & \\
\hline 166 & $\begin{array}{l}\text { Central African } \\
\text { Rep. }\end{array}$ & 5.95 & 4.8 & 0.3 & 0.36 & 4.8 & 2008 & 0.36 & & \\
\hline 167 & Chad & 6.68 & 6.16 & 0.21 & 0.36 & 6.16 & 2008 & 0.36 & & \\
\hline 168 & Guinea-Bissau & 6.94 & 5.71 & 0.2 & 0.36 & 5.68 & 1983 & 0.23 & & \\
\hline 169 & Liberia & 6.55 & 5.9 & 0.31 & 0.36 & 5.9 & 2008 & 0.36 & & \\
\hline 170 & Mali & 6.71 & 6.54 & 0.19 & 0.36 & 6.54 & 2008 & 0.36 & & \\
\hline 171 & Afghanistan & 7.69 & 6.6 & 0.23 & 0.35 & 6.6 & 2008 & 0.35 & & \\
\hline 172 & Burundi & 6.8 & 4.59 & 0.2 & 0.33 & 4.59 & 2008 & 0.33 & & \\
\hline 173 & Sierra Leone & 5.86 & 5.2 & 0.27 & 0.33 & 5.2 & 2008 & 0.33 & & \\
\hline 174 & Niger & 7.89 & 7.12 & 0.16 & 0.31 & 7.12 & 2008 & 0.31 & & \\
\hline 175 & Congo & 6.37 & 6.03 & 0.34 & 0.3 & 6.03 & 2008 & 0.3 & & \\
\hline 176 & Zimbabwe & 7.4 & 3.43 & 0.29 & 0.13 & 3.43 & 2008 & 0.13 & & \\
\hline
\end{tabular}


Appendix Figure A.1a. Cross-country relationship between total fertility rate (TFR) and Human Development Index (HDI), year 2008: Data points and a lowess curve fitted to the data. Figure A.1 illustrates that the positive association between the TFR and the HDI is observed at HDI levels above 0.85, independently of the scaling used in Figure 1.

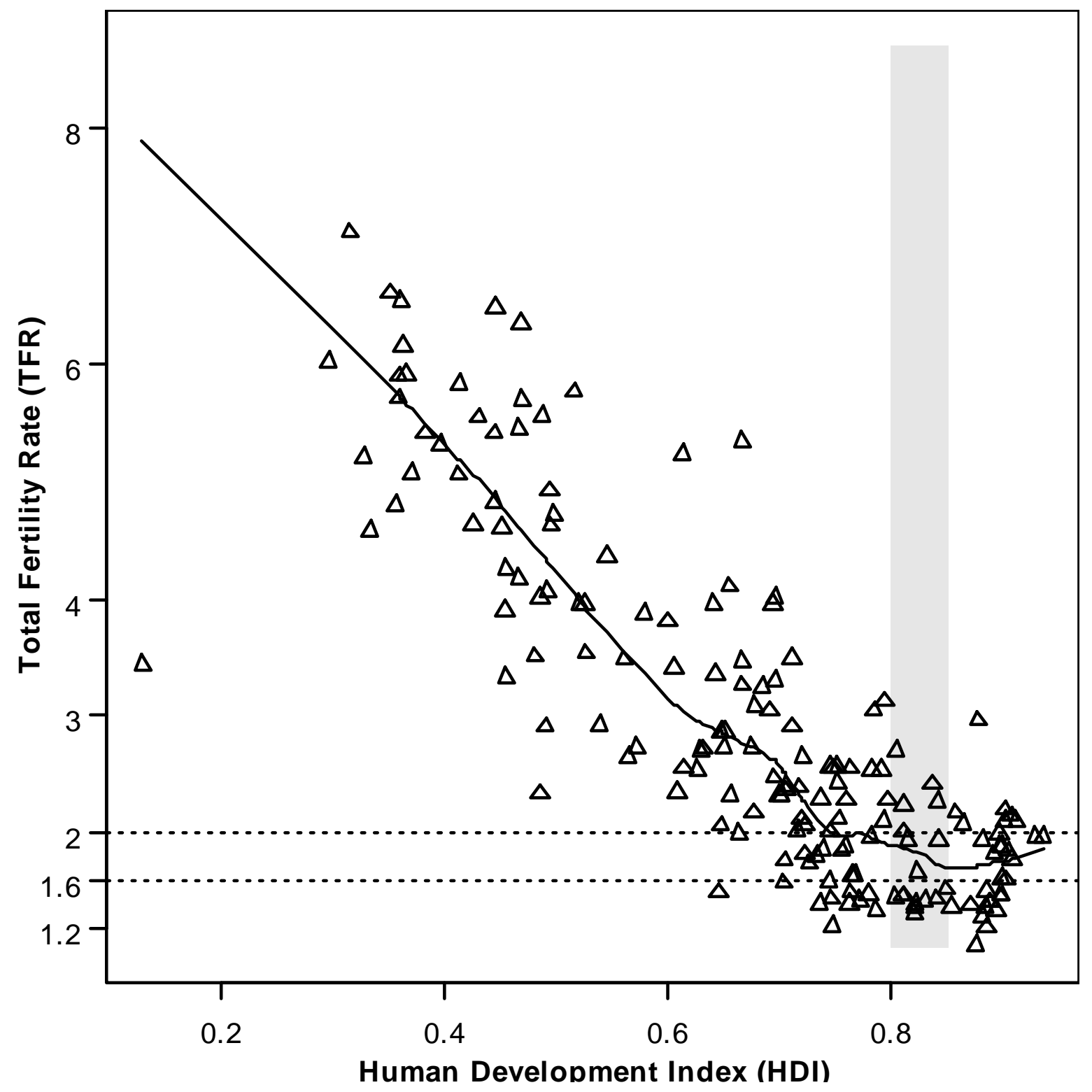

Notes:

(1) Countries with an HDI in the range of 0.80-0.84 in 2008 are in alphabetical order: Argentina, Chile, Croatia, Czech Republic, Estonia, Hungary, Latvia, Libya, Lithuania, Malta, Poland, Qatar, Slovakia, Uruguay.

(2) Countries with an HDI of at least 0.85 in 2008 are in alphabetical order: Australia, Austria, Belgium, Brunei Darussalam, Canada, Denmark, Finland, France, Germany, Greece, Hong Kong, Iceland, Ireland, Israel, Italy, Japan, South Korea, Kuwait, Luxembourg, the Netherlands, New Zealand, Norway, Portugal, Singapore, Slovenia, Spain, Sweden, Switzerland, the United Kingdom, the United States. 
Appendix Figure A.1b. Cross-country relationship between total fertility rate (TFR) and Human Development Index (HDI), year 2008: Data points and a lowess curve fitted to the data and a 95\% confidence interval for the lowess curve estimated using bootstrap

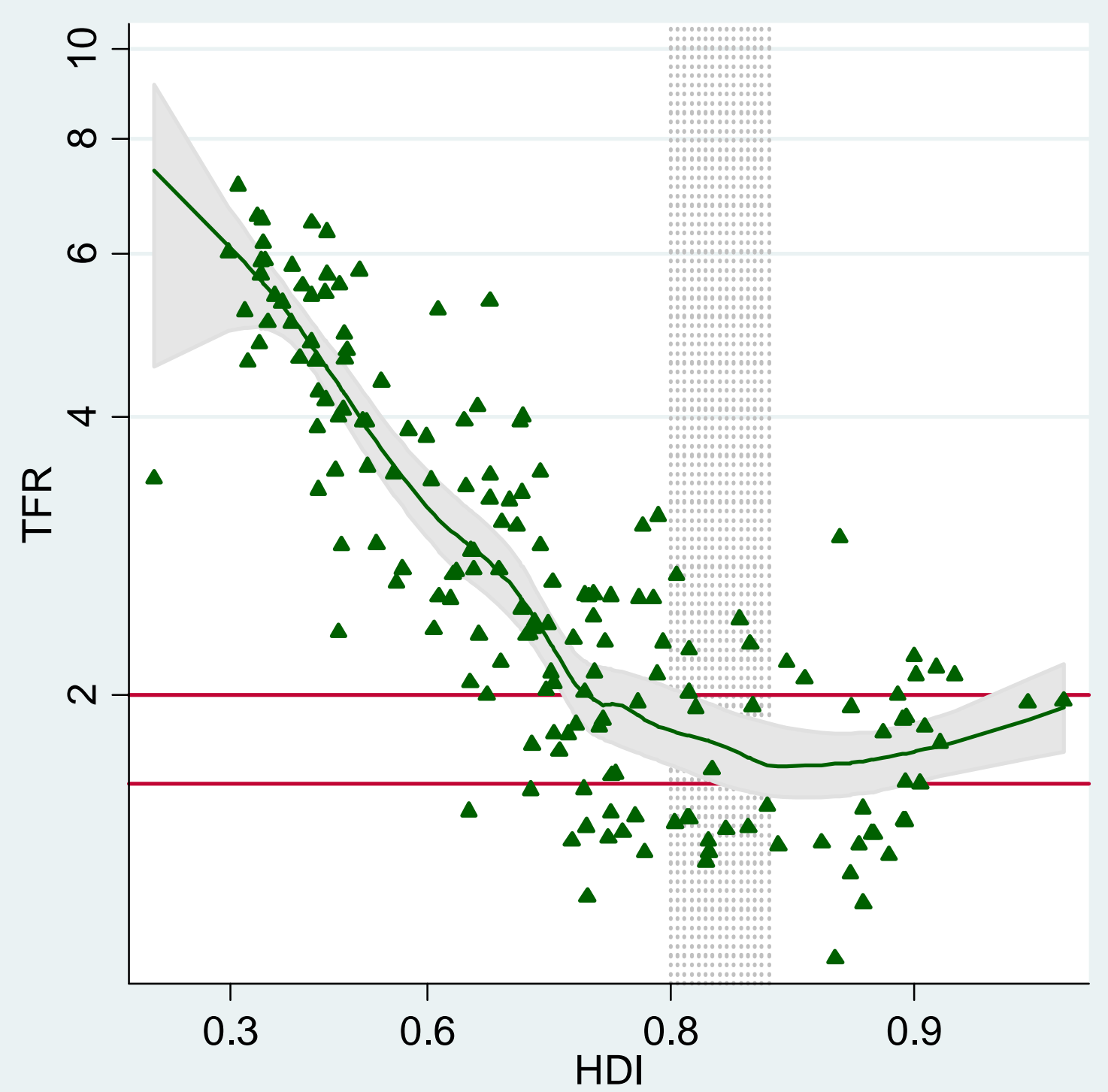

(1) The axes are scaled in the same manner as in Figure 1. 


\section{Appendix Figure A.2. Cross-country relationship between fertility by age and the Human Development Index (HDI), years 1985 and 2005. Panel A: Ages 15-29; Panel B: Ages 30 and above.}

PANEL A: HDI and Fertility at ages 15-29

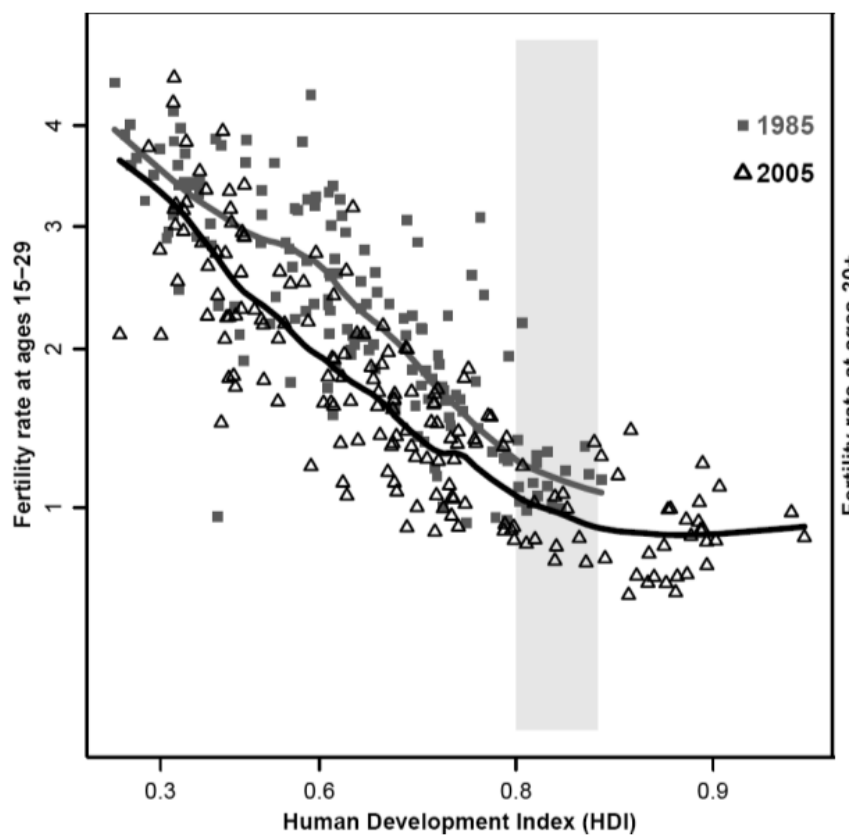

PANEL B: HDI and Fertility at ages 30-49

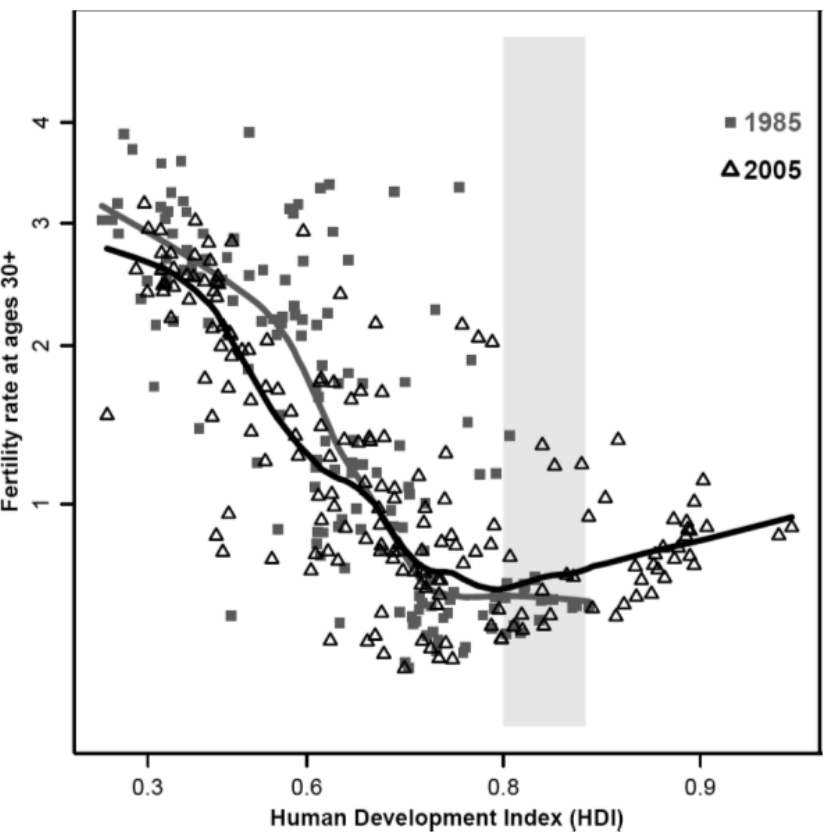

Notes:

(1) As in Figure 1 the axes are scaled using log-transformations as follows: $x$-axis scaling: TFR $*=\log (1+0.49 *$ TFR $) / 31$; y-axis scaling: HDI*=-log(1-hdi).

(2) We confirmed the flattening of the fertility-HDI relationship for ages below 30 and the reversal from negative to positive for ages 30 and above at high HDI levels by calculating the Kendall tau rank correlation between age-specific fertility and the HDI for the year 2005. For fertility at ages 15-29 the correlations were $-0.56(\mathrm{n}=130, \mathrm{p}<.001), 0.00(\mathrm{n}=13, \mathrm{p}>.10)$ and $0.17(\mathrm{n}=29, \mathrm{p}>.10)$ for the HDI ranges <0.80, 0.80-0.84, and $>=0.85$, respectively. For fertility at ages $30-49$ the correlations were $-0.54(\mathrm{n}=127, \mathrm{p}<.001), 0.30(\mathrm{n}=$ $13, \mathrm{p}>.10)$ and $0.31(\mathrm{n}=29, \mathrm{p}<.05)$ for the HDI ranges $<0.80,0.80-0.84$, and $>=0.85$, respectively. 
Figure A.3. Predicted TFR and tempo-adjusted TFR trajectories by HDI, and scatter plot of TFR and HDI in 2008 for 35 countries. Data sources: HDI UNDP. TFR World Bank Development Indicators. Mean age at birth: Own calculations based on data sources listed in the Appendix.

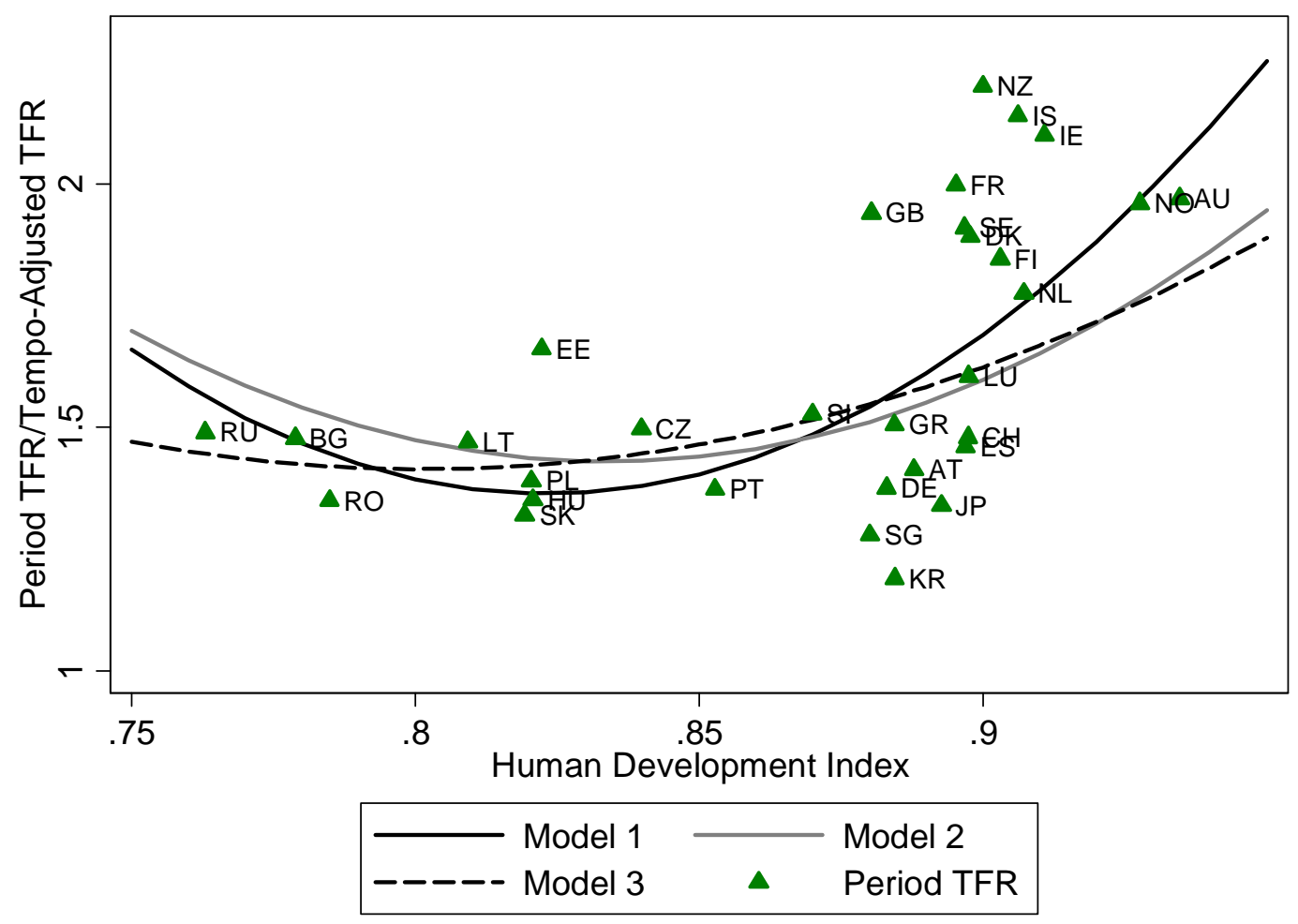

Model 1: Panel regression of TFR on HDI and HDI^2 with controls for country and time fixed effects. Coefficients for both HDI and HDI^2 are statistically significant $(\mathrm{p}<.001)$; R2 (within) $=0.41$.

Model 2: Panel regression of TFR on HDI and HDI^2 with controls for country and time fixed effects and additional controls for the first and the second differences in the mean age at birth. The coefficients for both HDI and HDI^$\wedge 2$ are statistically significant $(\mathrm{p}<.001)$, and for the first- and the second-order changes they are significant at the threshold $\mathrm{p}=.01 ; \mathrm{R} 2$ (within) $=0.48$.

Model 3: Panel regression of tempo-adjusted TFR on HDI and HDI^2 with controls for country and time fixed effects. The coefficients for both HDI and HDI^2 are significant $(\mathrm{p}<.05)$; R2 (within) $=0.27$.

\section{Notes}

(1) Models 1 and 2 include the countries for which annual time series are available for the TFR, the HDI, and the mean age at birth, and which have reached the HDI level of 0.75. These countries are: Australia, Austria, Belgium, Bulgaria, Canada, Czech Republic, Denmark, Estonia, Finland, France, Germany, Greece, Hungary, Iceland, Ireland, Italy, Japan, Lithuania, Luxembourg, the Netherlands, New Zealand, Norway, Poland, Portugal, Romania, Russian Federation, Singapore, Slovakia, Slovenia, South Korea, Spain, Sweden, Switzerland, the United Kingdom, the United States.

(2) Model 3 includes all countries for which annual time series are available for the tempo-adjusted TFR and the HDI, and which have reached the HDI level of 0.75. These 16 countries are: Austria, Bulgaria, Canada, Czech Republic, Estonia, Finland, Hungary, Lithuania, the Netherlands, Portugal, Russian Federation, Slovakia, Slovenia, Sweden, Switzerland, the United States. 
Appendix Figure A.4. Predicted TFR trajectories by HDI, and a scatter plot of TFR and HDI in 2008 for 35 countries. Data sources: HDI UNDP. TFR World Bank Development Indicators. Mean age at birth: Own calculations based on data sources listed in the Appendix.

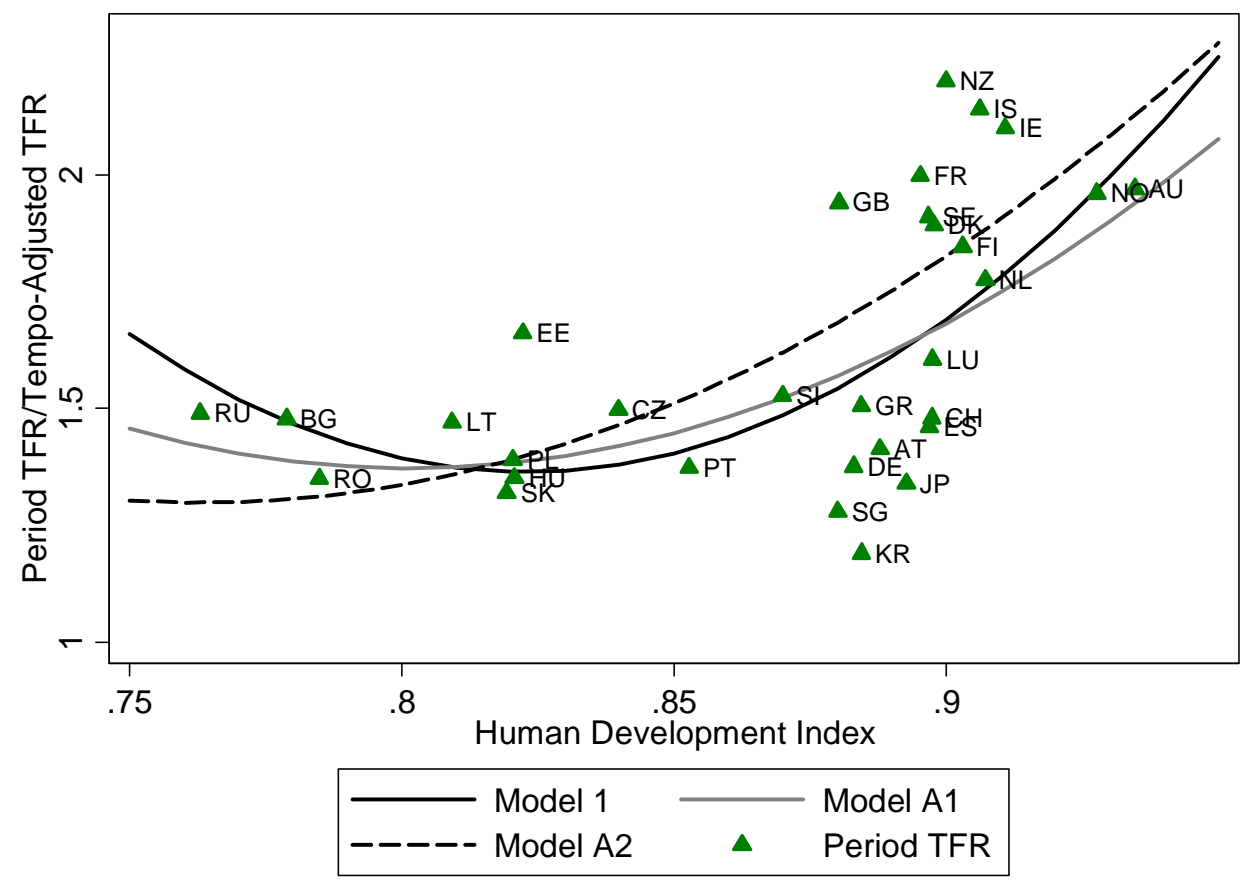

Model 1: Panel regression of the TFR on HDI and squared HDI with indicator controls for country and time fixed effects. Number of countries and data points 35 and 962. Coefficients for both HDI and HDI squared are statistically significant $(\mathrm{p}<.001) ; \mathrm{R} 2$ (within) $=0.41$.

Model A2: Panel regression of the TFR on HDI and squared HDI with controls for country fixed effects and country-specific time trends. Number of countries and data points 35 and 962. The coefficients for both HDI and HDI squared are statistically significant $(\mathrm{p}<.05)$; R2 (within) $=0.72$.

Model A3: Panel regression of TFR on HDI and squared HDI with indicator controls for country and time fixed effects and additional controls for the first and the second differences in the mean age at first birth. The coefficients for both HDI and HDI squared are statistically significant $(\mathrm{p}<.10)$; R2 (within) $=0.73$.

\section{Notes}

(1) Models 1 and 2 include all of the countries for which annual time series are available for the TFR, the HDI, and the mean age at birth, and which have reached the HDI level of 0.75. These countries are:

Australia, Austria, Belgium, Bulgaria, Canada, Czech Republic, Denmark, Estonia, Finland, France, Germany, Greece, Hungary, Iceland, Ireland, Italy, Japan, Lithuania, Luxembourg, the Netherlands, New Zealand, Norway, Poland, Portugal, Romania, Russian Federation, Singapore, Slovakia, Slovenia, South Korea, Spain, Sweden, Switzerland, the United Kingdom, the United States.

(2) Model 3 includes all of the countries for which annual time series are available for the TFR, the HDI, and the mean age at first birth, and which have reached the HDI level of 0.75. These 16 countries are: Austria, Bulgaria, Canada, Czech Republic, Estonia, Finland, Hungary, Lithuania, the Netherlands, Portugal, Russian Federation, Slovakia, Slovenia, Sweden, Switzerland, the United States. 
Figure A.5. Pace of TFR increase with respect to HDI (slope) and gender equality. Data sources: Global Gender Gap Index: World Economic Forum. Pace of TFR with respect to HDI: Own calculations based on data from UNDP (HDI), World Bank Development Indicators, and Human Fertility Database (TFR).

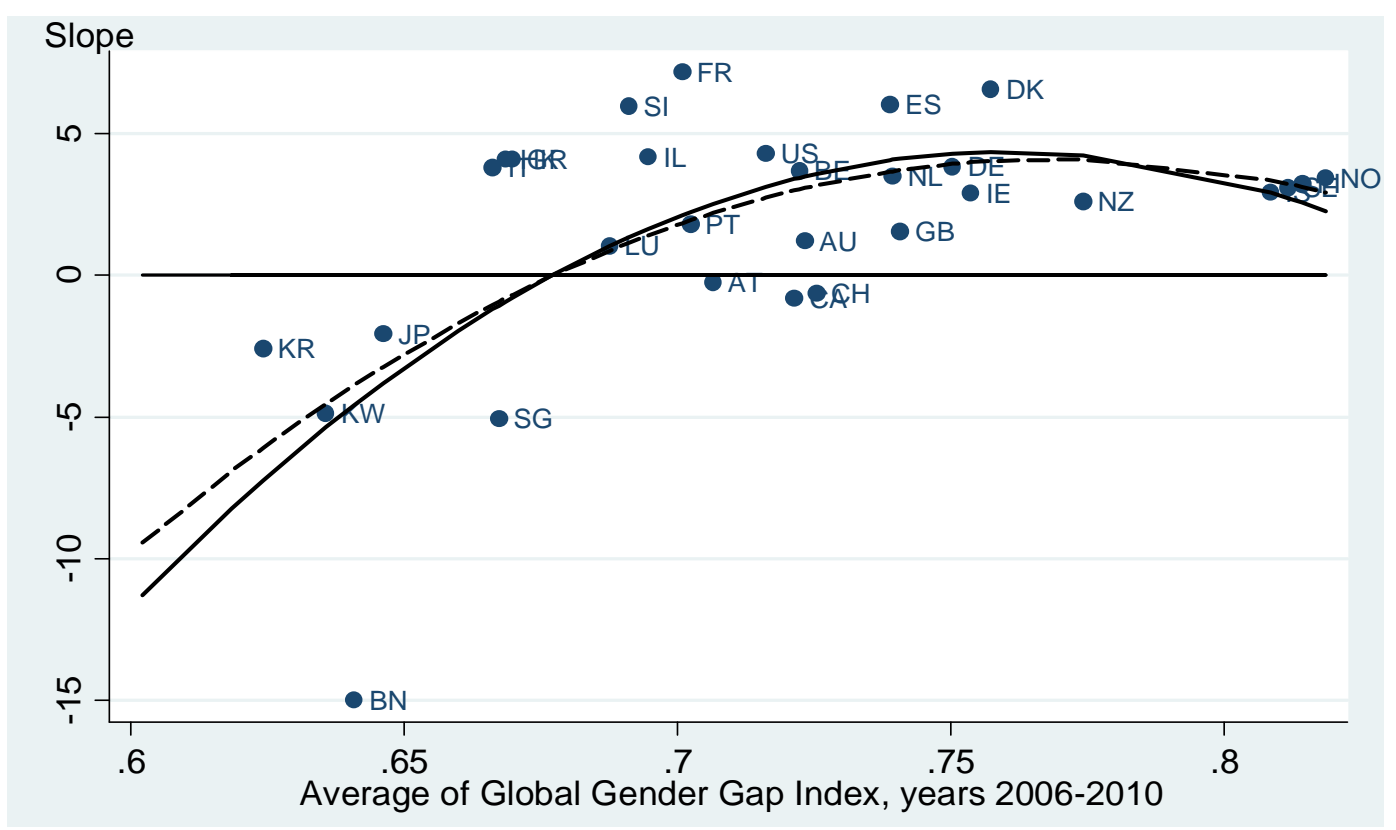

Solid line: Model 1, Regression of the pace of the TFR increase with respect to the HDI on the GGG and the squared GGG. The coefficients for both the GGG and the GGG squared are statistically significant $(\mathrm{p}<.05)$; $\mathrm{R} 2=0.35$.

Dashed line: Model 2, Regression of the pace of the TFR increase with respect to the HDI on the GGG and the squared GGG with additional controls for the TFR in the reference year. The coefficients for both the GGG and the GGG squared are statistically significant $(\mathrm{p}<.05) ; \mathrm{R} 2=0.53$.

Notes:

(1) Vertical axis: Pace of the TFR with respect to a unit change in the HDI at advanced HDI levels.

(2) Horizontal axis: Global Gender Gap (GGG) index averaged over 2006-2010.

(3) Pace of the TFR with respect to the HDI is calculated as the change in the TFR divided by the change in the HDI after the year in which the HDI was in the range of 0.80-0.84 and the TFR was at its lowest level within this HDI window (see Figure 3 for additional details). 


\section{Appendix Figure A.6. Completed fertility for the 1970 birth cohort, HDI, and Gender Equality. Data sources: HDI UNDP. Completed cohort fertility: Own calculations based on data sources listed in Table A.1. Global Gender Gap (GGG) index, World Economic Forum.}

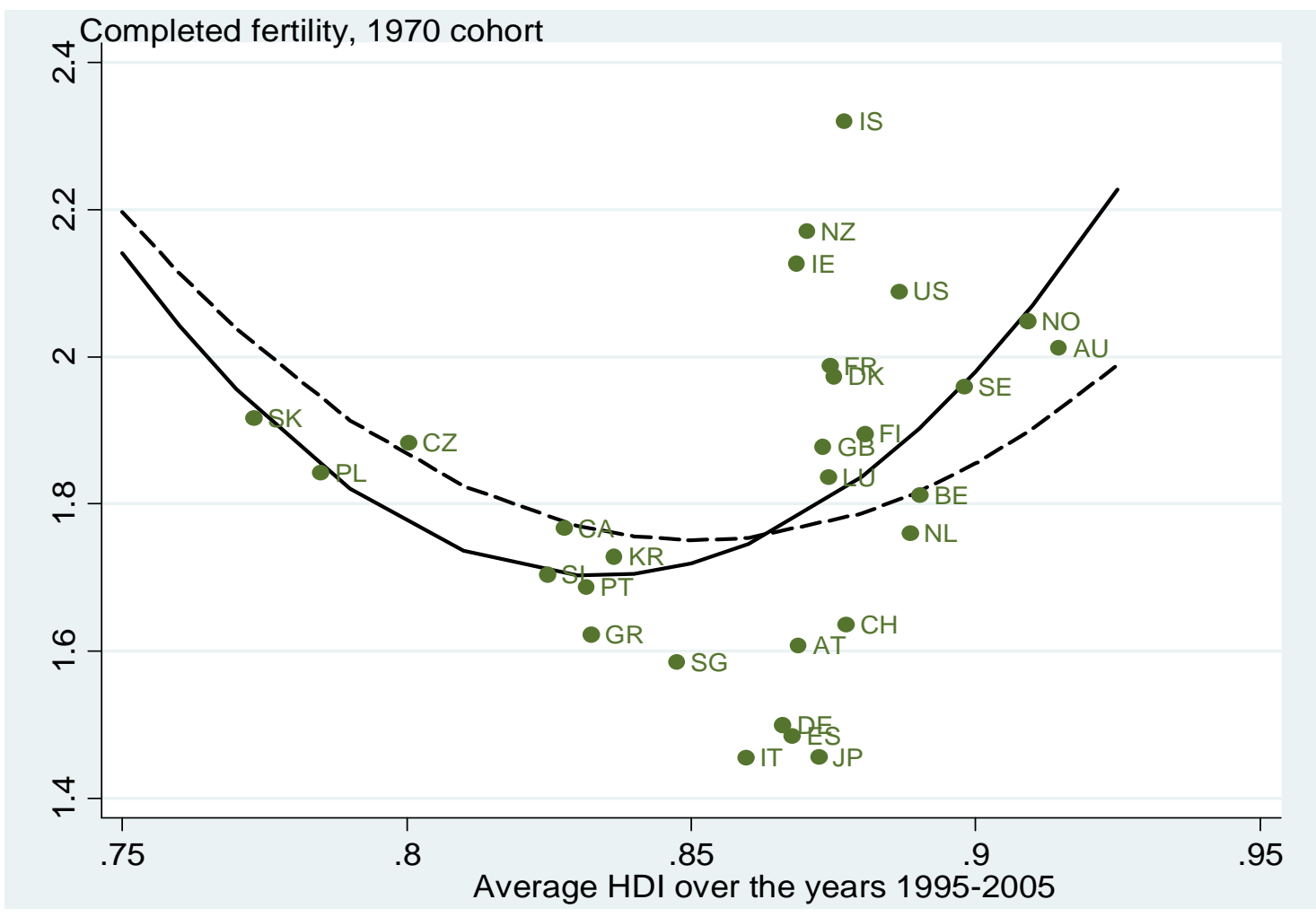

Solid line: Model 1, Regression of cohort fertility on the HDI and the squared HDI. The coefficients for both the HDI and the HDI squared are statistically significant $(\mathrm{p}<.05) ; \mathrm{R} 2=0.21$.

Dashed line: Model 2, Regression of cohort fertility on the HDI, the squared HDI and the gender equality index GGG. The coefficients for both the GGG and the GGG squared are significant $(\mathrm{p}<.10)$; R2 =0.40.

Notes:

(1) The figure shows the association between completed fertility for the 1970 birth cohort and the average HDI for the years 1995-2005 when the 1970 cohorts were in their prime childbearing years, or aged 25-35.

(2) Cohort fertility is estimated using the simple and conservative "freeze rates" method in which the last observed age-specific rates are extrapolated into the future (Myrskylä et al. 2013).

(3) The countries included are all of the countries for which the relevant data are available (the gender equality index, the HDI, and the fertility rates on an annual basis for single year age groups from 1985, when the 1970 cohort was aged 15, to 2008). The countries are Slovakia, Poland, Czech Republic, Slovenia, South Korea, Greece, Portugal, Canada, Singapore, Ireland, Italy, Luxembourg, Spain, New Zealand, Iceland, Denmark, Germany, Austria, Finland, Switzerland, Japan, France, Sweden, the United Kingdom, the United States, Belgium, the Netherlands, Norway, Australia, Norway, Australia. 